\title{
Distribution of Stage-Specific Neurite-Associated Proteins in the Developing Murine Nervous System Recognized by a Monoclonal Antibody
}

\author{
Miyuki Yamamoto, Anne M. Boyer, James E. Crandall, Michael Edwards, and Hideaki Tanaka* \\ Departments of Neuropathology and Biochemistry, Eunice Kennedy Shriver Center, Waltham, Massachusetts \\ 02254, and Department of Neurology, Harvard Medical School, Boston, Massachusetts 02115, and *Department \\ of Pharmacology, University of Gumma, Medical School, Maebashi, Japan
}

\begin{abstract}
A monoclonal antibody, 4D7, obtained with embryonic rat brain as an immunogen, recognizes an epitope on 3 protein species of $150-160,100-110$, and $80 \mathrm{kDa}$, present in mouse and rat brain during the fetal period. Vital immunostaining of dissociated cultures of fetal forebrain indicates that the antigen is localized largely on the external plasma membrane of a subpopulation of neurites. Immunocytochemistry reveals that the distribution of the antigen in vivo is restricted to the nervous system. Immunoreactivity is concentrated primarily in the pathways of a limited set of CNS and PNS axon systems during early stages of their development, as delineated by staining with the neurofilament antibody, C2. Depending on the particular axon system, immunoreactivity with $4 D 7$ persists only for one to several days of prenatal or perinatal development. In the spinal cord, stage-specific-neurite-associated proteins (SNAP) expression occurs first along motor axon pathways on embryonic day (E) 10 and then within the nerve trunks of dorsal root ganglia and the commissural fiber system on E11. Immunoreactivity is detectable among most cranial nerves starting in the interval from E11 to E13. Within the brain, the onset of SNAP expression within several discrete axon tracts occurs in the interval E1416 , including the lateral olfactory tract, anterior commissure, corpus callosum, fasciculus retroflexus, and fornix. Immunoreactivity within the embryonic intermediate zones of some structures matches the location of certain other axon systems. Sites of 4D7 staining which do not correspond to the location of axon populations include the internal portion of the external granular layer of the postnatal cerebellum and the cortex of the reeler mutant mouse. The predominant localization of the 4D7 antigen among axon systems and its precisely regulated spatiotemporal pattern of expression are consistent with the possibility that the SNAP antigens play a significant role in the early stages of growth of axonal tracts in vivo.
\end{abstract}

In the last decade, intensive research efforts have been directed towards finding molecules that are involved in regulating axonal growth. One major approach has been to look for substances present in conditioned media of cultured cells or in tissue extracts that promote neurite outgrowth from dissociated or explanted neuronal cells in vitro. In addition to NGF, a number of protein species responsible for such effects are currently under

Received Jan. 27, 1986; revised Apr. 28, 1986; accepted May 6, 1986.

We thank Drs. V. Caviness, R. McCluer, and G. Schwarting for helpful discussions, Mrs. J. Whitcomb for technical assistance, and Dr. M. Raff for GFAP antibody. This work was supported by NIH Grants HD05515, EY04549, and NS20213.

Correspondence should be addressed to Miyuki Yamamoto, E. K. Shriver Center, 200 Trapelo Rd., Waltham, MA 02254.

Copyright (C) 1986 Society for Neuroscience $0270-6474 / 86 / 123576-19 \$ 02.00 / 0$ investigation (Berg, 1984; Thoenen and Edgar, 1985). Some of the identified neurite-promoting factors correspond to known components of extracellular matrices, including the glycoprotein laminin and fibronectin, heparin sulfate proteoglycans, and diverse species of gangliosides (Byrne et al., 1983; Carbonetto, 1984).

An alternative approach is to generate antibodies that reveal the stage-dependent expression of antigens associated with growing axons. Several studies have described such axon-associated antigens in developing invertebrate (Goodman et al., 1984; McKay et al., 1984) and vertebrate species (Cole and Glaser, 1984; Ellis et al., 1985; Fujita and Obata, 1984; HenkeFahle and Bonhoeffer, 1983; Hockfield and McKay, 1985; Rosner et al., 1985; Rutishauscr ct al., 1978; Stallcup et al., 1985; Tanaka and Obata, 1984; Thiery et al., 1985). Moreover, antibodies to some of these antigens applied to in vitro or in vivo systems have been shown to block or perturb the pattern of axonal growth (Fischer et al., 1986; Henke-Fahle and Bonhoeffer, 1983; Rutishauser et al., 1978; Silver and Rutishauser, 1984; Stallcup and Beasley, 1985a; Thanos et al., 1984). In the present study, we present evidence that the monoclonal antibody, 4D7, recognizes protein species that are expressed transiently in association with a restricted set of axon systems in the murine CNS and PNS during fetal and early postnatal periods. These heretofore undescribed antigens, termed the stagespecific neurite-associated proteins (SNAP), are good candidates for regulators of axonal outgrowth in vivo.

Some of the results in the present paper have previously been presented in abstract form (Edwards and Yamamoto, 1985; Yamamoto et al., 1985).

\section{Materials and Methods}

\section{Animals}

BALB/c mice and timed-pregnant Sprague-Dawley rats were obtained from the Charles River Breeding Laboratory. Embryonic and adult mice of C3B6 hybrid strain (C57B $\times \mathrm{C} 3 \mathrm{H})$, maintained in the Shriver animal colony, were the primary source of tissuc for antigen identification and all histological studies. Embryonic Sprague-Dawley rats were the source of the immunogen. For both rat and mouse embryos, the day of conception was designated embryonic day (E) 0 and the day of birth E19, or postnatal day (P) 0 . Measures of crown-rump length were used to confirm the developmental stage (Lauder and Bloom, 1974; Wahlsten and Wainwright, 1977). A minimum of 3 mouse embryos each at each day from E9 to birth and 2 mice each at P4, P6, P14, and adulthood were processed for immunocytochemistry. For comparison, 2 E15 and E17 rat embryos and adult rats were also processed. For biochemical studies, brain tissue from E13, E15, E17, P4, and adult mice and from E13, E15, and adult rats was used. 


\section{Production of monoclonal antibodies $4 D 7$ and $C 2$}

$\mathrm{BALB} / \mathrm{c}$ mice were injected intravenously 3-4 times at 2 week intervals with a living cell suspension prepared from the cerebra of E15-17 rat embryos. Polyinosilic and polycytidilic acid (20-30 $\mu \mathrm{g}$ /injection) were used as an adjuvant. Three to 4 days following the final injection, the mice were sacrificed, and spleen cells were then fused with NS-1 myeloma cells by the method of Köhler and Milstein (1975). The 4D7 antibody was selected by immunocytochemical screening of hybridoma supernatants on cryostat sections obtained from the forebrain of fresh-frozen embryonic mice. The 4D7 antibody was found to be of the IgM subclass by using subclass specific secondary antibody (Boehringer-Mannheim). The $\mathrm{C} 2$ antibody was generated similarly using a membrane preparation from embryonic chick spinal cord as the immunogen (Tanaka and Obata, 1984). According to a solid-phase binding assay, this antibody recognizes a constituent of neurofilaments extracted from adult mouse and rat brains (M. Yamamoto, H. Tanaka, and J. N. Wood, unpublished observations).

\section{Antigen characterization}

\section{Protein analysis}

The brains and spinal cords of C3B6 mice and Sprague-Dawley rats were dissected from developing or adult animals and homogenized in 50 mм Tris buffer (pH 6.7) containing 1\% Triton X100 and $0.34 \mathrm{M}$ sucrose at $0^{\circ} \mathrm{C}$ both in the presence and absence of protease inhibitors ( $5 \mathrm{~mm}$ EGTA, $1 \mathrm{~mm}$ PMSF, 0.1\% Aprotinin, $25 \mu \mathrm{m}$ leupeptin). After centrifugation at $5000 \mathrm{rpm}$ in a bench-top centrifuge, the supernatant was separated by SDS gel electrophoresis. Polypeptides were then transferred from the gel to nitrocellulose paper by the method of Towbin et al. (1979). The blots were then incubated for $30 \mathrm{~min}$ in PBS, pH 7.4, containing $10 \%$ normal goat serum (NGS), washed briefly with PBS containing $1 \%$ NGS (NGS-PBS), and then either incubated overnight at $4^{\circ} \mathrm{C}$ or for $2-3 \mathrm{hr}$ at room temperature with $4 \mathrm{D} 7$ supernatant. Subsequently, the paper was washed with NGS-PBS $(3 \times 10 \mathrm{~min})$, incubated for $2 \mathrm{hr}$ at room temperature with anti-mouse $\operatorname{IgM}$ (1:1000 in PBS), washed with PBS $(3 \times 10 \mathrm{~min})$, and reacted with $0.05 \% 3,3^{\prime}$-diaminobenzidine-tetrahydrochloride (DAB, Toyobo) and $0.002 \% \mathrm{H}_{2} \mathrm{O}_{2}$. As controls, incubation of the nitrocellulose paper with 4D7 antibody was replaced by incubation with either PBS containing $1 \%$ NGS or with a mouse IgM supernatant that reacts only with embryonic myoblasts.

\section{Glycolipid analysis}

Brain tissue was homogenized in chloroform/methanol (1:1). The extracted lipid fraction was dried under nitrogen, resuspended in distilled water, and desalted on Bond-Elut cartridges (Williams and McClure, 1980). The desalted glycolipids were chromatographed on DEAE-Sephadex A-25 (Pharmacia) to separate neutral glycolipids from gangliosides (Ledeen and Eng, 1973). The fraction containing neutral glycolipids was treated with $0.6 \mathrm{M}$ methanolic $\mathrm{NaOH}$ for $1 \mathrm{hr}$ at $20^{\circ} \mathrm{C}$, neutralized with $0.5 \mathrm{M} \mathrm{HCl}$, and desalted. Neutral glycolipids and gangliosides were separately chromatographed on aluminum high-performance thin-layer chromatograph plates (Merck) in chloroform/methanol/water, 60:35:8 ( $\mathrm{vol} / \mathrm{vol})$, dried, and then dipped in $0.05 \%$ polyisobutyl methacrylate in hexane (Brockhaus et al., 1981). The plates were then soaked in PBS containing 1\% BSA for $2 \mathrm{hr}$ before exposure to anti-4D7 antibody for $2 \mathrm{hr}$ at $4^{\circ} \mathrm{C}$. After the plates were washed in PBS, they were reacted with peroxidase conjugated anti-mouse IgM for $2 \mathrm{hr}$ at $4^{\circ} \mathrm{C}$. The plates then were washed in PBS and reacted for $20 \mathrm{~min}$ with $33 \mathrm{~mm}$ 4-chloronaphthol in $0.02 \mathrm{M}$ Tris- $\mathrm{HCl}$ buffer containing $20 \%$ methanol and $0.025 \%$ $\mathrm{H}_{2} \mathrm{O}_{2}$.

\section{Tissue culture}

Cells were dissociated from the spinal cords and brain stems of E1315 rat embryos by incubation in $0.025 \%$ trypsin and trituration. Cells were then plated on $35 \mathrm{~mm}$ plastic dishes precoated with laminin (20 $\mu \mathrm{g} /$ dish; Bethesda Research Laboratories). They were maintained in serum-free medium consisting of $50 \mathrm{ml}$ of F12 and $43 \mathrm{ml}$ of Earle's salt modified Eagle's medium. Additives included glucose ( $44 \mathrm{~mm})$, penicillin/streptomycin (20 units/ml), glutamine $(2.0 \mathrm{~mm})$, selenium dioxide $(30 \mathrm{nM})$, progesterone $(20 \mathrm{nM})$, insulin $(5 \mu \mathrm{g} / \mathrm{ml})$, and putrescine dihydrochloride $(100 \mu \mathrm{M})$.

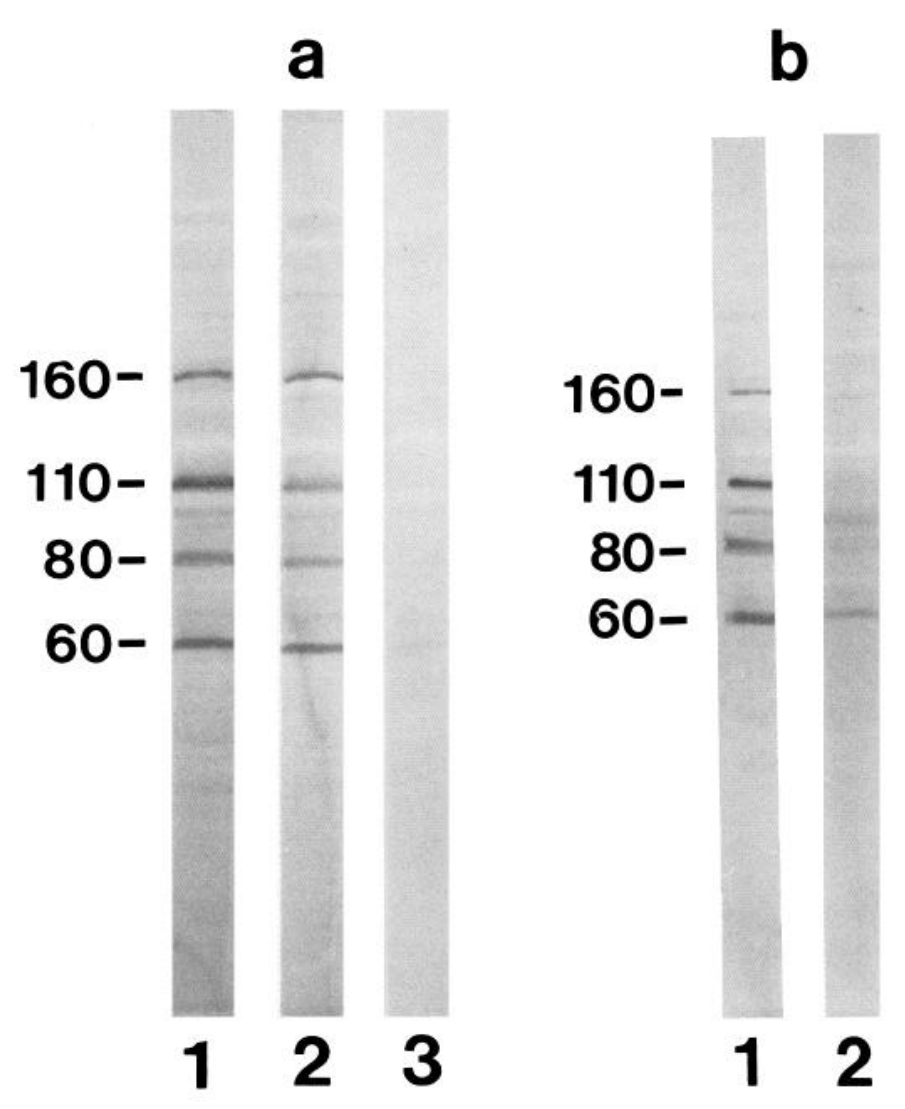

Figure 1. Western blots of brain homogenate reacted with 4D7 antibody. $a$, Comparison of E13 mouse (lane 1) and E15 rat (lane 2). Estimated molecular weights of 4 positive bands in both blots are indicated (in $\mathrm{kDa}$ ). In the control blot (lane 3), E13 mouse proteins blotted on nitrocellulose paper were reacted only with peroxidase-conjugated antimouse IgM. $b$, Comparison of E13 (lane 1 ) and adult mouse (lane 2). Note that a $60 \mathrm{kDa}$ band present in blots of embryonic brain is also detectable in the control and adult blots.

\section{Immunocytochemistry}

\section{Tissue sections}

Intact mouse or rat embryos were frozen in isopentane chilled by dry ice and sectioned by cryostat at $10 \mu \mathrm{m}$. The sections were thaw-mounted on gelatin-chrome alum-coated slides, air-dried, and stored at $-20^{\circ} \mathrm{C}$ for subsequent immunocytochemical staining. Fixation with $2 \%$ paraformaldehyde for 5-10 min at room temperature produced the same staining pattern as unfixed tissue and was adopted as the method of fixation for the 4D7 antibody. For C2 antibody staining, only unfixed sections or sections fixed with acetone for $5 \mathrm{~min}$ at room temperature were used. After fixation, sections were washed with PBS $(3 \times 5 \mathrm{~min})$ and incubated overnight at $4^{\circ} \mathrm{C}$ with $4 \mathrm{D} 7$ or $\mathrm{C} 2$ supernatants. Following a wash with NGS-PBS $(3 \times 5 \mathrm{~min})$, the sections were incubated for $1-$ $2 \mathrm{hr}$ at room temperature with peroxidase conjugated anti-mouse IgM (Boehringer-Mannheim; 1:50 in NGS-PBS). They were then washed with $\mathrm{PBS}$, and reacted for $20 \mathrm{~min}$ with $0.05 \% \mathrm{DAB}$ and $0.002 \% \mathrm{H}_{2} \mathrm{O}_{2}$. After washing with PBS, the DAB reaction product was intensified either with an exposure for $3-5 \mathrm{~min}$ to $0.01 \% \mathrm{OsO}_{4}$ solution or with Gallyas' physical developer (Liposits et al., 1984). Sections were then dehydrated in a series of alcohols, cleared in xylene, and coverslipped with Permount. Some of the sections were lightly counterstained with cresyl violet.

\section{Primary tissue culture}

For vital staining, cultures were exposed to the 4D7 antibody (purified IgM fraction, $1 \mathrm{mg} / \mathrm{ml}$, diluted $1: 40$ in Hank's salt solution) at $37^{\circ} \mathrm{C}$ for $30 \mathrm{~min}$. The cultures were washed with Hank's solution $(3 \times 5 \mathrm{~min})$ 

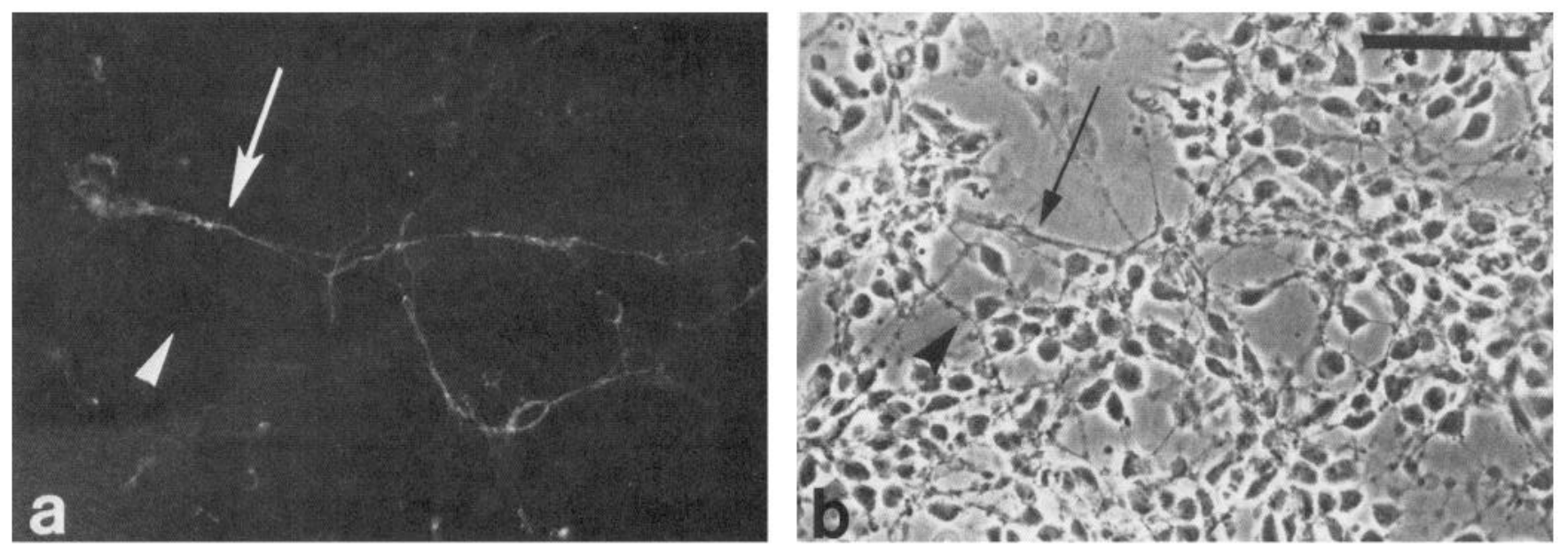

Figure 2. Dissociated cell culture of E14 rat brain stem stained with 4D7 antibody by indirect immunofluorescence. Two days after plating on laminin-coated dish, the culture was incubated with 4D7 supernatant diluted 1:1 with Hank's solution followed by fixation with acetone and ethanol (1:1). $a$ and $b$, Fluorescence and phase views, respectively, of the same field. Arrows indicate corresponding neurites stained with 4D7 antibody; arrowheads indicate unstained neurites. Scale bar, $100 \mu \mathrm{m}$.

and fixed within a $1: 1$ solution of acetone and ethanol at $-20^{\circ} \mathrm{C}$ for 5 min and washed with PBS. Following an incubation with fluorescein isothiocyanate (FITC) conjugated anti-mouse IgM (Boehringer-Mannheim; $1: 50$ in $1 \%$ NGS-PBS), some of the cultures were fixed with $2 \%$ paraformaldehyde before incubation with 4D7 antibody. The cultures were examined under epifluorescent and phase-contrast illumination.

\section{Results}

\section{Antigen characterization}

The 4D7 antigen has been assessed by glycolipid and protein immunoblotting of the mouse brain at E13, E15, E17, P6, P14, and adulthood and rat brain at E15-16 and adulthood. No immunoreactivity is observed in glycolipid blots. In Western blots of proteins from fetal mouse and rat brains, 3 distinct immunoreactive bands are present at 150-160, 100-110, and $80 \mathrm{kDa}$ (Fig. 1a). In postnatal mouse brain, these bands are observed only when cerebellar tissue is analyzed. In Western blots of adult mouse (Fig. 1b, lane 2) and rat brain proteins, these bands are either not detected or exhibit very low levels of immunoreactivity. Besides these protein species recognized by 4D7 antibody, one other band is observed at about $60 \mathrm{kDa}$. Unlike the higher-molecular-weight bands, it is more consistently detected in blots of adult brain, and it also appears weakly on control blots processed only with $1 \%$ normal goat serum followed by the peroxidase-conjugated secondary antibody to mouse IgM (Fig. 1a, lane 3). Control blots processed with an IgM monoclonal antibody recognizing only myoblasts also show only weak staining of a $60 \mathrm{kDa}$ band. Thus, it is uncertain whether the $60 \mathrm{kDa}$ species represents a specific antigen recognized by the 4D7 antibody.

The presence of protease inhibitors does not alter the pattern of immunoreactive bands in Western blots. Therefore, none of the polypeptides recognized by the 4D7 antibody is likely to correspond to products of proteolysis during processing.

\section{Localization of antigen expression in cultured cells}

In primary tissue culture prepared from E13-15 rat spinal cord with vital immunostaining, a subpopulation of long and thin processes originating from neuron-like cells is labeled with 4D7 antibody (Fig. 2). The somata show less intense staining. In cultures fixed with paraformaldehyde, a similar pattern of staining is observed. These results indicate that the epitope recognized by the 4D7 antibody is exposed on the outside of the membrane of neurites. Very rarely, a few of the flat cells are labeled with 4D7 antibody; however, 4D7-positive processes were not double-labeled following immunostaining of these cultures with antibody to the glial fibrillary acidic protein (GFAP).

\section{Immunocytochemical localization of 4D7 antigen in the developing nervous system}

The temporospatial pattern of expression of the 4D7 antigen has been determined through immunocytochemistry on serial cryostat sections of whole mouse embryos at daily intervals from E9 to birth (P0) and of isolated brains at selected postnatal ages. In order to localize antigen expression in relation to axon systems, alternate sections were stained with the neurofilament antibody C2 (M. Yamamoto, H. Tanaka, and J. N. Wood, unpublished observations).

The most striking aspect of the in vivo expression of the 4D7 antigen is that, with few exceptions, its distribution is restricted to the sites of a limited number of PNS and CNS fiber tracts during the fetal period. Staining outside the nervous system is not detectable. Based on this general finding and the results in tissue culture, the antigens are designated SNAP. In the CNS and PNS regions that express SNAP immunoreactivity (Fig. 3), the onset of detectable staining either coincides with or follows closely in time the appearance of neurofilament immunoreactivity at the same locations. The time course of loss of 4D7 staining varies greatly among the sites of SNAP expression, but most immunoreactivity is lost by birth (Fig. 3). Thus, SNAP expression is associated with the early outgrowth of particular axonal systems. Details of the temporospatial pattern of SNAP expression are described in following sections on the spinal cord, cranial nerves, and brain.

\section{Spinal cord}

As illustrated schematically in Figure 3, the time course of SNAP expression by neurons and axonal systems of the spinal cord and periphery follows a general progression from motoneurons to commissural interneurons to dorsal root ganglion cells.

On E9, when neurofilament immunoreactivity is not detectable in the mouse spinal cord (Cochard and Paulin, 1984), no 4D7 immunoreactivity is observed.

From E10 to E11, immunostaining with the neurofilament antibody $\mathrm{C} 2$ (Fig. $4, b, d, f$ ) reveals that increasing numbers of motoneurons accumulate in the ventrolateral cord (cervical through thoracic levels) and project their axons through the ventral roots into somitic mesenchyme. In the same interval, 


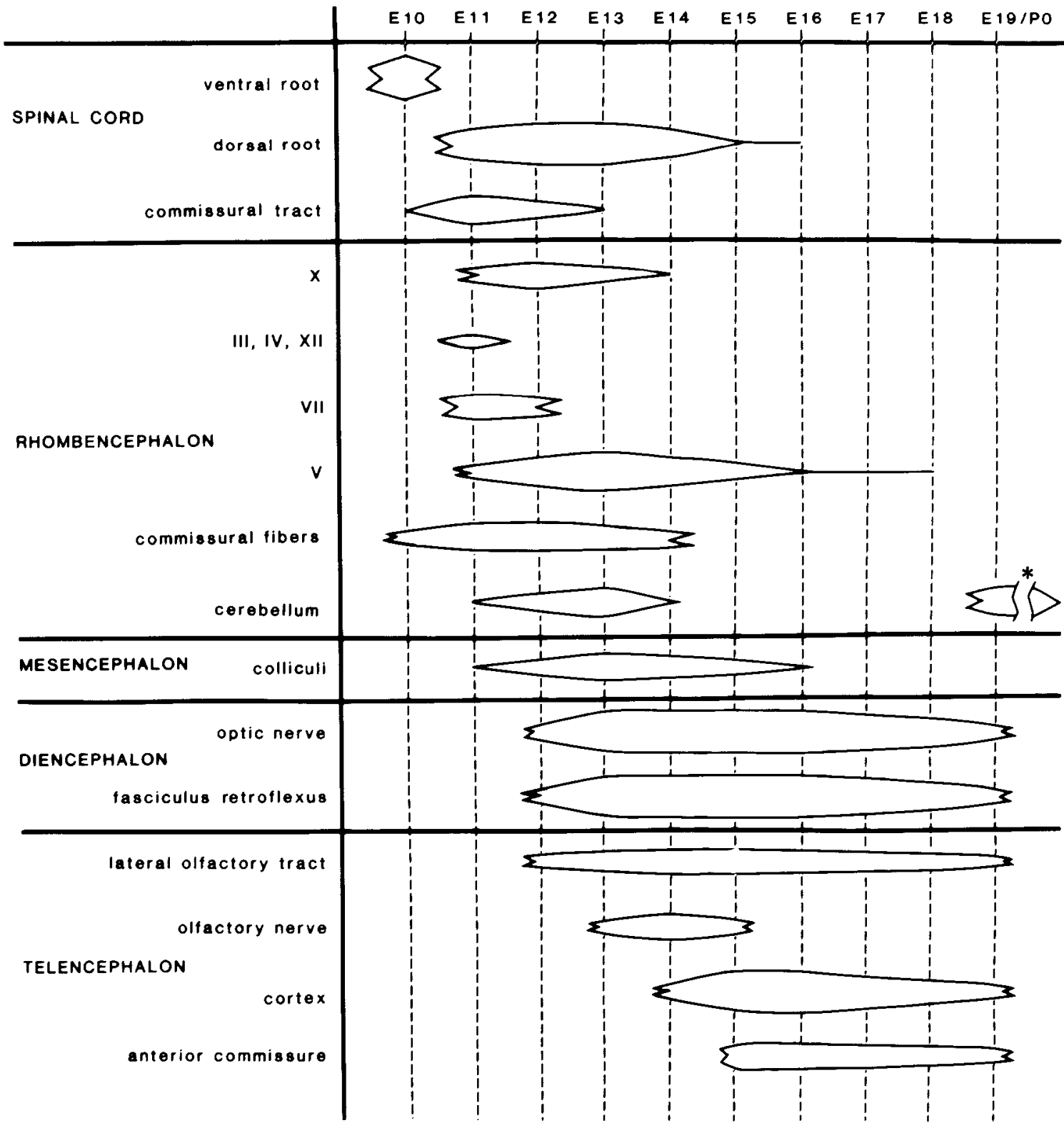

Figure 3. Chart of time course of SNAP expression in various structures of the nervous system. Width of bars provides an indication of relative intensity of 4D7 immunoreactivity on the days sampled (vertical dotted lines). Jagged lines at ends of bars reflects uncertainty as to exact time point of onset or termination of SNAP expression between sample days. For the cerebellum, note the gap of several days between the loss of immunoreactivity in the fetal intermediate zone and the appearance of staining in the external granular layer neonatally. The latter lasts to P6 but is absent by P14 (asterisk marks a break in the time scale).

the centrally directed processes of dorsal root ganglia (DRG) invade the dorsal horn, and their peripheral processes merge with ventral roots to form spinal nerves. The development of the commissural fiber system is also evident. C2-stained axons course ventrally along the lateral surface of the cord and then extend as fascicles between the lateral motor column and the germinal ventricular zones to cross in the ventral commissure (arrow in Fig. $4 b$ ). This set of findings is consistent with previous anatomical studies on spinal cord development in the mouse using silver staining, Golgi staining, scanning electron microscopy (Holley, 1982; Holley et al., 1982a, b; Nornes and Carry, 1978; Sims and Vaughn, 1979; Wentworth, 1984a, b; Wentworth and Hinds, 1978), and immunocytochemistry with antineurofilament antibody (Cochard and Paulin, 1984).

In contrast to $\mathrm{C} 2$ staining, striking transformations in the pattern of SNAP expression occur in the spinal cord between E10 and E11. At E10, the 4D7 antibody stains the motor neurons weakly and their axon tracts prominently, whereas the DRGs and their axon tracts are negative (Fig. $4, a, c$ ). The change in the distribution of 4D7 immunoreactivity by E11 includes a complete loss of staining associated with motoneurons and ventral roots and an emergence of immunoreactivity in DRG nerve trunks and along the route occupied by commissural fibers (Fig. $4 e$ ). Staining is particularly prominent at the dorsal root entry zones, apparently corresponding to the dorsal funiculus. Unlike the appearance of fiber fascicles delineated by C.2 staining, 4D7 immunoreactivity in sensory and motor roots exhibits a meshlike or reticular pattern (Fig. $4, c, d$ ). The 4D7 immunoreactivity along the route of the commissural tract appears instead as tangentially aligned strands (Fig. $4 e$ ), indicative of an association 

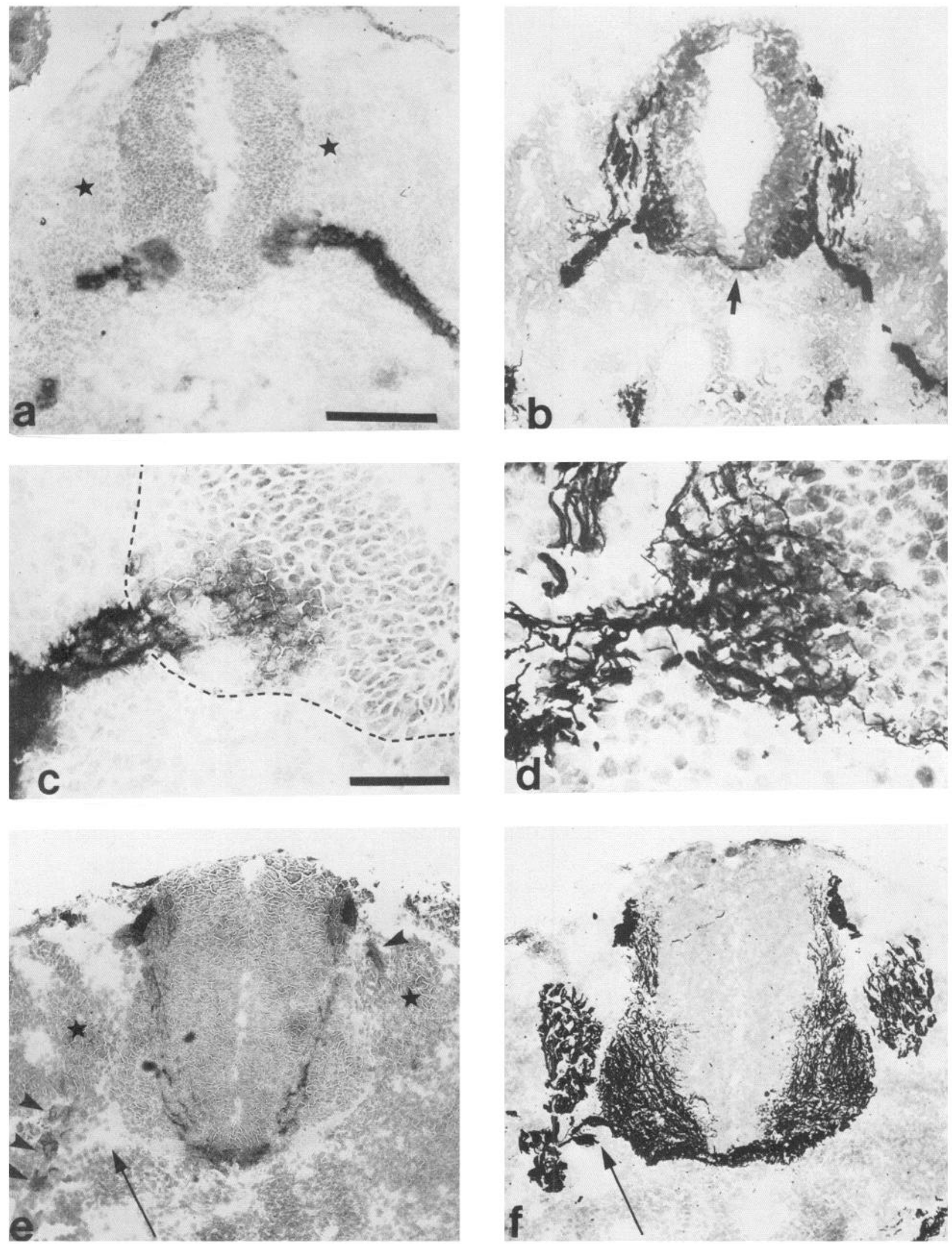

Figure 4. Comparative distribution of SNAP and neurofilament immunoreactivity in the spinal cord and peripheral nerves at E10-11 stained immunocytochemically with antibodies 4D7 (left) and C2 (right), respectively. Unless otherwise indicated, micrographs shown here and subsequently are of alternate sections counterstained lightly with cresyl violet. $a$ and $b$, Coronal views of lumbar cord showing 4D7 staining of the ventral horn and root. The dorsal root ganglia (star marks in 4D7 stained section) contain C2-stained axons but are negative for 4D7 (stars). The same is true of the developing ventral commissure (arrow in $b$ ). $c$ and $d$, High-magnification views of the ventral horn and root. In $c$, note the stronger 4D7 
with axons rather than with migratory neurons that traverse this zone.

The 4D7 staining of the central and peripheral processes of DRGs persists relatively unchanged from E11 to E13 and subsequently diminishes and disappears by E17. Staining of the commissural system with 4D7 diminishes sharply by E12, is barely detectable on E13, and is absent on E14.

At the sacral level of the spinal cord, the time course of $\mathrm{C} 2$ and 4D7 staining is delayed about $2 \mathrm{~d}$ with respect to morc rostral levels, a result that probably reflects the delayed development of caudalmost spinal cord from the tailbud through "secondary neurulation" (Schoenwolf, 1984).

SNAP expression is never associated with sympathetic ganglia and ncrves or with parasympathetic ncurons of the periphery, as located in sections immunostained with C2 (cf. Ayer-LeLievre et al., 1985).

\section{Cranial nerves}

Expression of SN $\Lambda \mathrm{P}$ is detectable in most cranial nerves starting at or shortly after the time of earliest axonal outgrowth detected by staining with the neurofilament antibody $\mathrm{C} 2$. Results will be presented first for trigeminal and optic cranial nerves, both of which showed relatively prolonged and intense expression of SNAP.

The entry of the trigeminal sensory root into the ventrolateral rhombencephalon is evident with C2-immunostaining on E10, but 4D7 stains only the site of axon fascicles within the ventral periphery of the ganglion at this age (Fig. 5, $a, b$ ). The root and the peripheral nerves throughout their extent show an increasing intensity of 4D7 immunoreactivity between E11 and E13 (Fig. $5, e, g)$. SNAP expression is detectable in fine processes of the $V$ th nerve near the skin at E13 (Fig. 5, $g, h$ ) and in the muzzle, apparently corresponding to small axon fascicles innervating vibrissae follicles at E14 (arrows in lower left of Fig. 6, $a, b$ ). Subsequently, SNAP expression declines in the trigeminal system over a prolonged period extending through E18.

In the primary visual system, weak 4D7 staining is first detected along the ventral periphery of the optic stalk on E12 (Fig. $7 a$ ), which corresponds to the site occupied by the first wave of C2-stained axon fascicles from the eye (Fig. $7 b$ ) (Edwards et al., 1986a). By E13, when the leading front of fascicles has just crossed through the optic chiasm and additional fascicles have arrived in the ventral stalk (cf. Edwards et al., 1986a; Silver, 1984), the distribution of $4 \mathrm{D} 7$ and $C 2$ staining corresponds closely (Fig. 7, $c-f$ ). The 4D7 immunoreactivity, however, is meshlike and wispy in appearance compared to sharp delineation of axon fascicles revealed with $\mathrm{C} 2$ staining (Fig. $7, e, f$ ). Between E14 and P0, 4D7 staining persists in the stalk (optic nerve after E15; e.g., arrowheads in Fig. $6, a, b$ ), but at each age immunoreactivity consistently declines below detectability within the optic tract between the chiasm and the ventrolateral geniculate nucleus (Fig. $7, g, h$ ). Also at each age sampled, 4D7 staining within the optic fiber layer of the retina, first evident on E13 (Fig. 7c), diminishes sharply with distance from the optic disk region.

Three cranial nerves exhibit moderate degrees of staining with the 4D7 antibody. The facial motor root (VII) shows 4D7 immunoreactivity only on E11 (Fig. $5 c$ ) and E12. The onset of SNAP expression coincides with the day $\mathrm{C} 2$ staining is first observed in this system (Fig. $5 d$ ). Portions of the central and peripheral nerve trunks of the vagus (X) are stained with 4D7 from E12 to E14, while weak staining within the ganglia is detectable only on E12. By comparison, C2 staining is first detected in this system $1 \mathrm{~d}$ earlier (E11). Finally, 4D7 staining delineates the route of olfactory axons between the olfactory epithelium and the olfactory bulb between E13 and E15. The primary olfactory axons, defined by staining with the $\mathrm{C} 2$ antibody, extend toward and invade the marginal zone of the bulb between E11 and E12 (i.e., 1-2 d earlier), a finding consistent with results of previous studies (Hinds, 1972). Somata of the olfactory neurons and the proximal and distal portions of the fiber trajectories within the epithelium and marginal layer of the olfactory bulb, respectively, do not show 4D7 immunorcactivity.

Other cranial nerves show very weak and brief SNAP expression (Fig. 3). The oculomotor (III), hypoglossal (XII), and glossopharyngeal (IX) roots exhibit detectable 4D7 staining only on E11. The acousticovestibular nerve (VIII) is negative at all ages (e.g., Fig. 5, $g, h$ ) except in 1 of 3 cases preparcd at E13 (silverintensified). The accessory (XI) and abducens (VI) motor roots could not be identified in the period from E11 to E13 but were observed to be negative for SNAP expression at E14 or older ages. The trochlear root (IV), identified starting on E11 in C2stained sections, consistently shows no detectable 4D7 immunoreactivity. However, considering the observation of 4D7 staining by all other identified cranial nerves, it is quite possible that a very brief period of SNAP expression in the trochlear nerve may have been missed.

\section{Brain}

\section{Rhombencephalon}

On E10, SNAP is expressed in the emerging intermediate zone (IZ) of the ventral rhombencephalon, a zone well delineated from the germinal ventricular zones by $\mathrm{C} 2$ immunostaining (Fig. $5, a, b)$. By E13, when the IZ is much thicker, 4D7 staining occupies superficial and deep margins of the IZ (Fig. $5, e, f$ ). As immunoreactivity is continuous across the midline, SNAP expression is inferred to be associated with a subset of commissural axon systems of the ventral rhombencephalon revealed by $\mathrm{C} 2$ staining (Fig. $5, b, d, f$ ). The $4 \mathrm{D} 7$ staining concentrated in the external layer of the lateral pons is also continuous with the entry zone of the trigeminal root and, in part, appears to correspond to the ascending and descending tract of V (Figs. 5, $e, g ; 6 a)$. Near the juncture of the pons with the midbrain tegmentum (Fig. $8 a$, arrowheads), this external pontine labeling merges with a line of clumps of 4D7 immunoreactivity, which probably constitute cells of the mesencephalic tract of $\mathrm{V}$ (Fig. $8 b$, arrow).

SNAP expression occurs in the cerebellum in 2 intervals separated by a period of an absence of expression (Fig. 3). The intermediate zone of the metencephalic plate shows barely detectable 4D7 immunoreactivity on E11 and E12. Such staining becomes prominent on E13, when it occupies the outer half to two thirds of the IZ of the cerebellar anlage, as defined by $\mathrm{C} 2$ staining (Fig. 8). The zone of immunoreactivity is continuous with the superficial pontine staining and, thus, could be associated with the developing trigeminocerebellar projection (either primary or secondary fibers). This projection has previously been inferred to be the source of the superficial rostrocaudally

\footnotetext{
immunoreactivity in the root compared to motoneuronal somata (perimeter of cord indicated by a dotted line) and the differences in morphological appearance of staining compared with that produced by $\mathrm{C} 2$ antibody $(d), e$ and $f$, Coronal views of cervical cord on E11. Compared to the broad distribution of $\mathrm{C} 2$ immunoreactivity, 4D7 selectively stains the peripheral and central processes (arrowheads) of DRG (stars), the dorsal root entry zone, and along the axonal trajectories of commissural interneurons. The motoneuronal pool and ventral root (arrowis) are negative with 4D7 antibody. Scale bars, $200 \mu \mathrm{m}(a, b, e, f)$ and $50 \mu \mathrm{m}(c, d)$.
} 

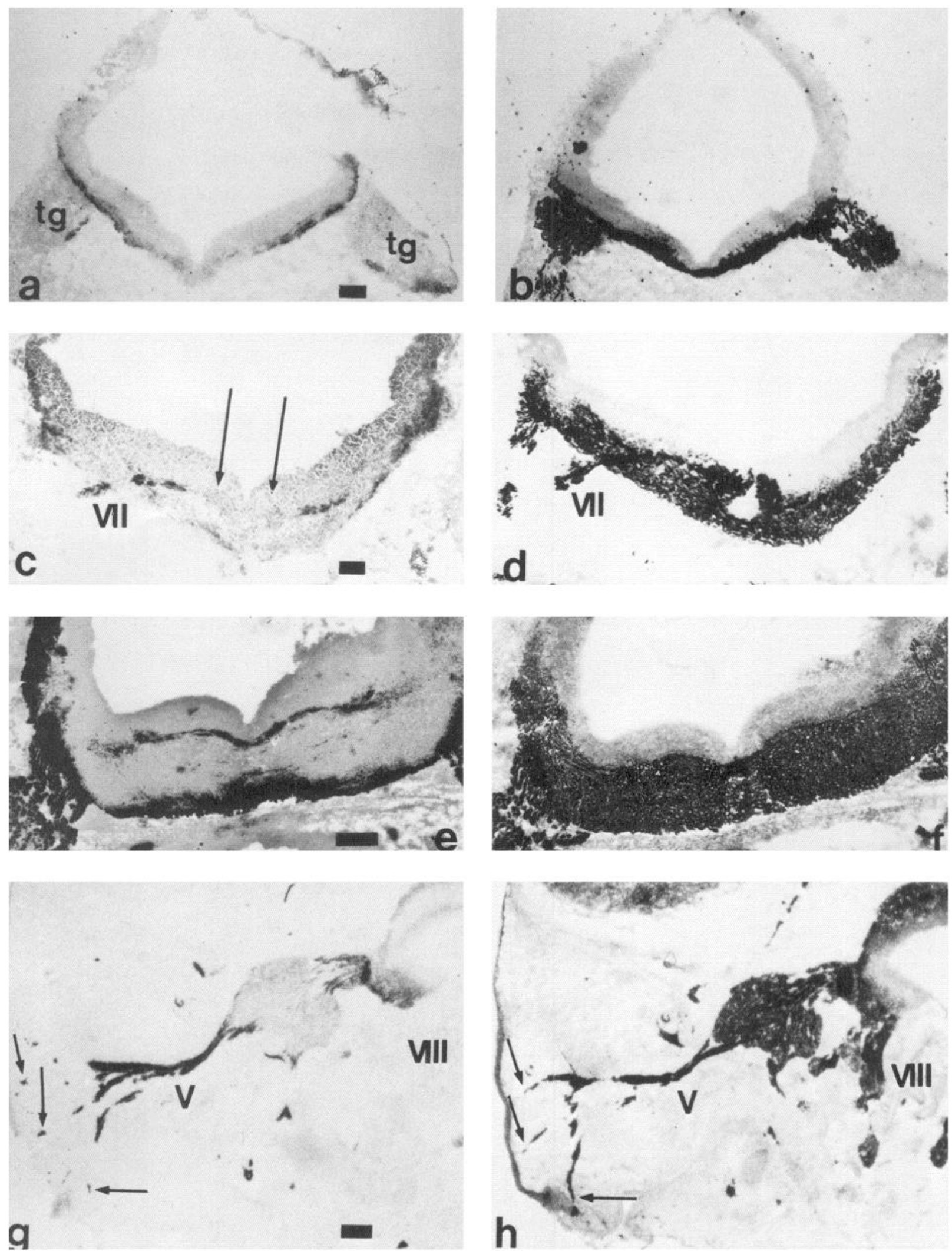

Figure 5. Immunocytochemical staining of ventral rhombencephalon and associated cranial nerves. Sections stained with 4D7 antibody on left and $\mathrm{C} 2$ on right. $a$ and $b$, Coronal section through rhombencephalon on E10. The intermediate zone emerging superficial to the ventricular zone is positive with both antibodies. Strands of $4 \mathrm{D} 7$ immunoreactivity $(a)$ appear within trigeminal ganglia $(t g)$ but not in the roots evident by $\mathrm{C} 2$ staining $(b) . c$ and $d$, Coronal sections through the medulla on E11. The central and peripheral portions of the facial motor root (VII) stain with both antibodies. The positions of the motor nuclei are indicated by arrows. Superficial 4D7 staining laterally is near the entry zone of the vagus nerve. $e$ and $f$, Horizontal sections through the pons on E13. The sensory trigeminal root and superficial and deep zones of the intermediate zone 

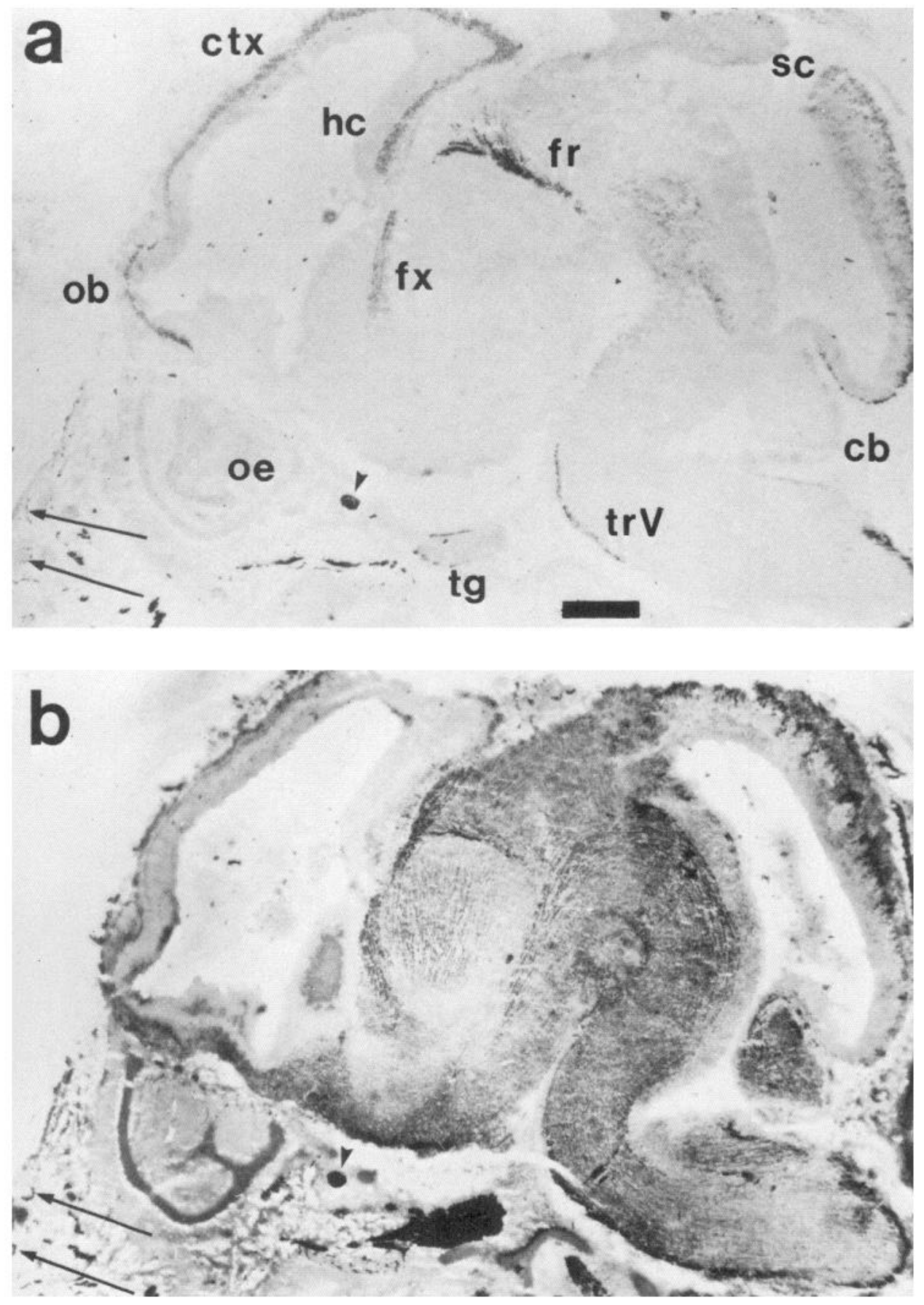

Figure 6. Low-magnification views of 4D7 and C2 immunostaining in sagittal sections of the brain on E14. Rostral is to the left. Discrete C2 stained fiber tracts $(b)$ that also show 4D7 immunoreactivity $(a)$ include the fasciculus retroflexus $(F R)$, fornix $(f x)$, descending tract of $\mathrm{V}(\operatorname{trV})$, and the optic nerve (arrowhead). The 4D7 staining in the intermediate zones of the olfactory bulb $(o b)$, superior colliculus ( $s c)$, neocortex $(c t x)$ and hippocampus $(h c)$ corresponds to particular axon-rich strata. Weak staining of the olfactory nerve and at the site of decussating axons in dorsorostral cerebellum $(c b)$ is not detectable at this magnification. Note dense 4D7 staining along the peripheral process of the trigeminal ganglion $(\mathrm{tg})$ and in fine trigeminal nerve fascicles innervating vibrissae follicles in the lower left (arrows). oe, olfactory epithelium. Scale bar, $500 \mu \mathrm{m}$.

oriented fiber system present in the mouse cerebellum at this stage of development (Tello, 1940). Alternatively (or, in addition), the 4D7 immunoreactivity could be associated with deep nuclear neurons, proposed to occupy the superficial IZ initially and later become displaced from the cerebellar surface by migrating Purkinje cells (Altman and Bayer, 1985). By E14, SNAP expression in the cerebellum is dramatically reduced (Fig. 6a) and is weakly detected only at a superficial rostromedial site. At this time, Purkinje cells are still migrating and the external granular layer is just beginning to form (Miale and Sidman, 1961).

Several days later, on P0, 4D7 immunoreactivity reappears in the deep one third to one half of the external granular layer. Such staining is still present on P6 (Fig. 9, $a, c$ ) but is absent

stain with 4D7 antibody $(e)$. The latter is continuous across the midline and corresponds to a subset of the commissural fiber tracts that stain with $\mathrm{C} 2(b) . g$ and $h$, Sagittal sections through the face and lateral rhombencephalon on E13. Rostral is to the left. The central and peripheral processes (V) of the trigeminal ganglion stain with both antibodies, but neuronal somata are negative with 4D7 antibody. Arrows indicate 4D7 and C2 immunoreactivity in the peripheral portion of the nerve. The acousticovestibular root (VIII), stained with C2 in $h$, is negative with 4D7 ( $g$; noncounterstained section). Arrows indicate site of optic stalk. Scale bars, $100 \mu \mathrm{m}(a-d)$, and $200 \mu \mathrm{m}(e-h)$. 

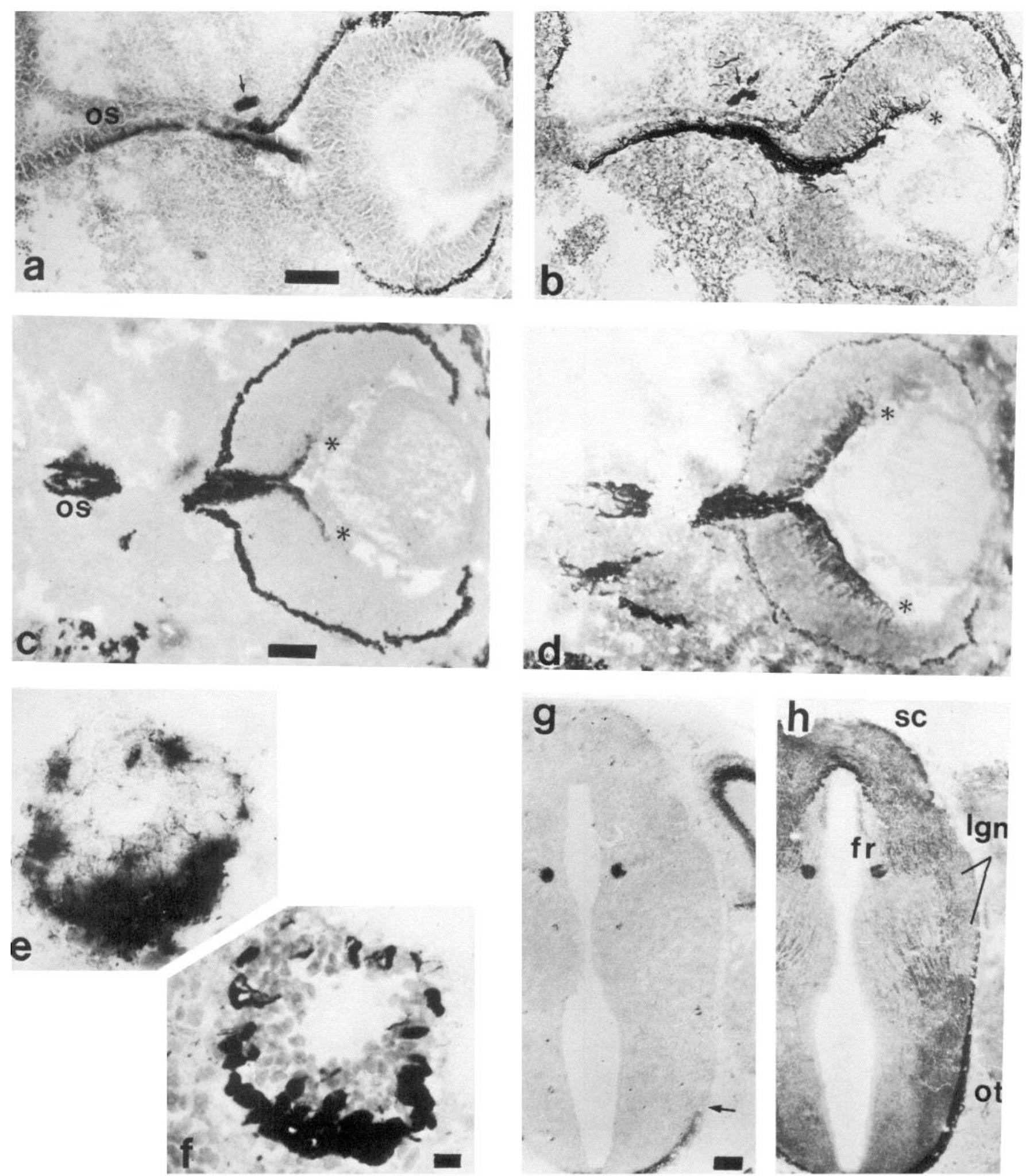

Figure 7. Immunocytochemical staining in the primary optic pathways. For each pair of micrographs, the section stained with 4D7 is on the left and with $\mathrm{C} 2$ on the right. $a$ and $b$, Coronal sections through the eye and optic stalk (os) on E12. C2-stained axons arise only from dorsocentral retina as far as the asterisk $(b)$ and extend along ventral optic stalk as far as its junction with ventral diencephalon. In a matched section from a different embryo (a), diffuse 4D7 immunoreactivity is restricted to the ventral optic stalk. Arrows point to portions of an oculomotor nerve. $c$ and $d$. Horizontal sections on E13 showing dense 4D7 staining along axon pathways in the optic disk and optic stalk and an absence of staining of much of the optic fiber layer occupied by $\mathrm{C} 2$-stained axons. Nasal retina is $u p$. $e$ and $f$, Enlarged sagittal views of the optic stalk halfway between the eye and brain. Immunoreactivity with 4D7 is concentrated in the ventral peripheral optic stalk (noncounterstained section) similar to C2stained axon bundles but differs in its meshlike appearance. $g$ and $h$, Coronal sections through diencephalon on E15. A sharp decrement in 4D7 staining occurs along the course of the postchiasmatic optic tract (arrow in $g$ ), whereas with $\mathrm{C} 2$ staining, the optic tract (ot) may be observed to extend over the lateral geniculate nuclei (lgn; dorsal and ventral indicated) and to reach the superior colliculus $(s c)$. Scale bars, $100 \mu \mathrm{m}(a-d), 10$ $\mu \mathrm{m}(e, f)$, and $200 \mu \mathrm{m}(g, h)$. 

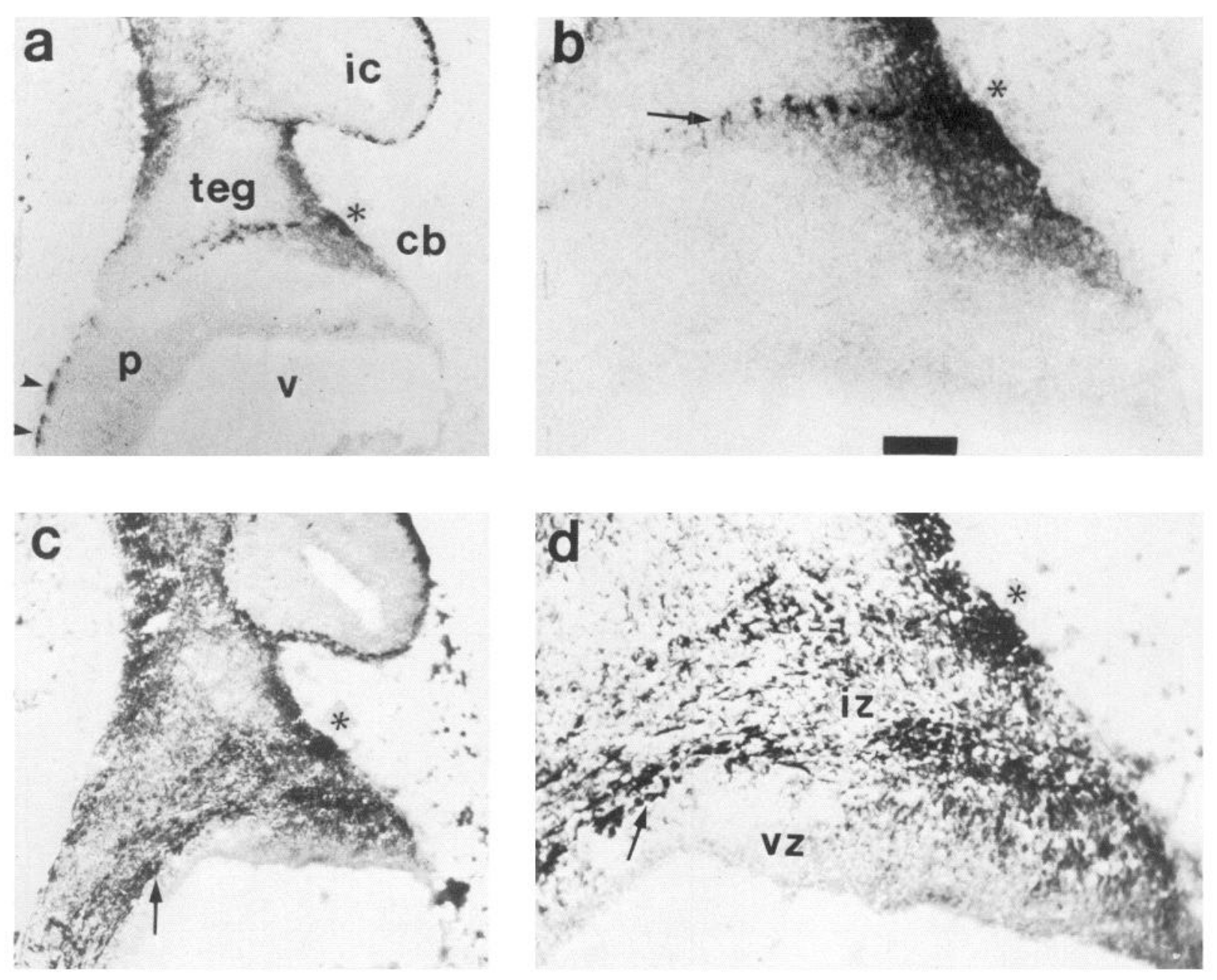

Figure 8. Immunocytochemical staining of the cerebellum on E13. Low- and high-magnification views ( $a, c$ and $b, d$, respectively) of sagittal sections stained with 4D7 and C2 antibodies ( $a, b$ and $c, d$, respectively). Asterisks indicate the rostral boundary of the cerebellar anlage ( $c b$ ) with the tegmentum $(t e g)$ and pons $(p)$. ic, Inferior colliculus; $v$, fourth ventricle. Staining with 4D7 occupies upper portions of the cerebellar intermediate zone ( $i z$ ) delineated by C2 staining. Dense clumps of 4D7 immunoreactivity along the line of the arrow in $b$ appear to correspond to cells of the mesencephalic tract of $\mathrm{V}$. The $\mathrm{C} 2$-stained longitudinal fiber system extending from the pons into the deep intermediate zone of the cerebellum (arrows in $c, d$ ) is negative with $4 \mathrm{D} 7$. Scale bars, $100 \mu \mathrm{m}$.

by P14. C2-stained axons become dense in the underlying "transitional molecular layer" (Altman, 1972) and sparse in the deeper cellular layers, but they are not detectable in the external granular layer (Fig. 9, $b, d$ ). Thus, this site of SNAP expression is clearly dissociated from axonal systems.

\section{Mesencephalon}

SNAP expression appears to be associated with a particular fiber stratum of the superior colliculus. Very weak 4D7 staining is present at the surface of the superior colliculus on E11 and becomes more prominent in the emerging intermediate zone on E12 and E13 (Fig. 10, $a, e$ ). At this time, its location correlates with that of a transversely oriented system of axon fascicles delineated by $\mathrm{C} 2$ staining (Fig. 10b). From E14 to E16, transversely oriented strands of weak 4D7 immunoreactivity are detectable at progressively deeper positions from the tectal surface (Figs. $6 a, 10 c$ ). Correspondingly, a system of transversely oriented fiber fascicles stained by $\mathrm{C} 2$ comes to lie below strata containing rostrocaudally oriented fiber fascicles (Figs. 6b, 10d). This transformation has been shown to reflect a precocious development of the deepest tectal stratum (stratum profundum) and its later displacement from the pial surface by the migration of cells that form the overlying layers (Edwards et al., 1986b).
The 4D7 immunoreactivity is associated only with the component of the fiber system in continuity with the lateral tegmentum (tectobulbar tract) and not with the component that courses ventromedially (predorsal bundle). SNAP expression in the superior colliculus becomes undetectable by E17.

The inferior colliculus shows SNAP expression over the same interval as the superior colliculus. On E14, staining is particularly intense in a superficial portion of the IZ occupied by transversely oriented axon fascicles (Fig. 10, $e-g$, see also Figs. 6, $a$, $b$ and $8, a, c)$. In contrast to $\mathrm{C} 2$ staining, however, 4D7 immunoreactivity also occupies a broad portion of deeper IZ, some of which appears to correspond to neurons (Fig. 10f). As the anlagen of the central nuclei develop first and are later displaced from an initially superficial position by cortical nuclear neurons (Repetto-Antoine and Meininger, 1982), it is possible the SNAP expression is associated transiently with central nuclear neurons, as well as with their axon pathways within the inferior colliculus.

\section{Diencephalon}

The habenulopeduncular tract (fasciculus retroflexus) shows weak 4D7 staining on E12, when the tract is first detected by C2 immunoreactivity, and relatively dense staining from E13 to E17 (Figs. 6, $a, b$ and 7, $g, h$; see also Fig. 11 $a$, arrowhead). 

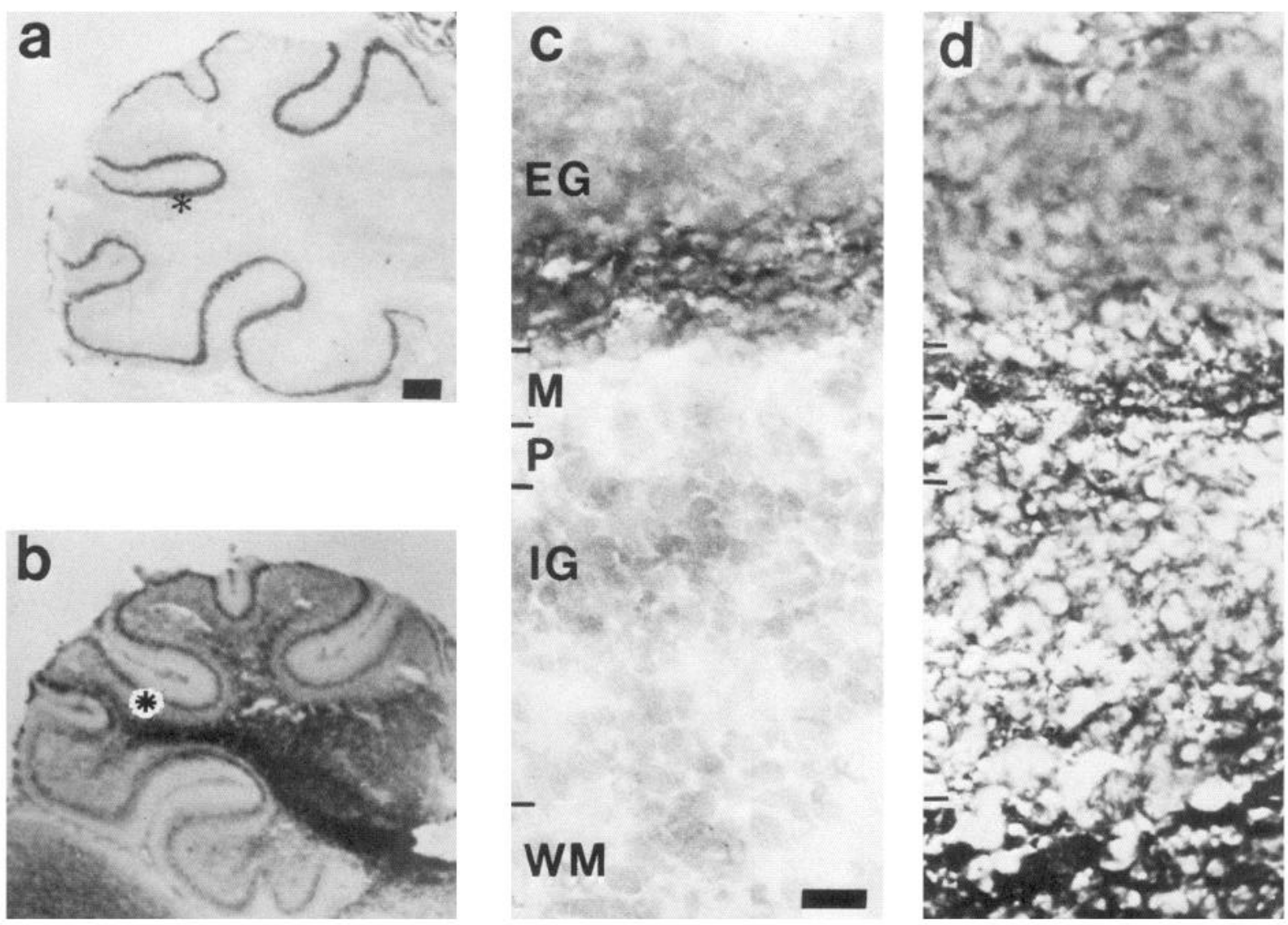

Figure 9. Immunocytochemical staining of the cerebellum on P6. Low- and high-magnification views of sagittal sections stained with 4D7 and $\mathrm{C} 2$ antibodies $(a, c$ and $b, d)$. Sectors through cerebellar cortex in $c$ and $d$ correspond to sites marked by asterisks in $a$ and $b$, respectively (cresyl violet counterstain filtered out in $a$ and $b$ ). Only the inner half of the external granular layer $(E G)$ stains with 4D7, whereas axonal processes stained with $\mathrm{C} 2$ are distributed densely in the transitional molecular layer $(M)$ and subcortical white matter $(W M)$ and sparsely in Purkinje and internal granular layers $(P$ and $I G)$. Scale bars, $200 \mu \mathrm{m}(a, b)$ and $20 \mu \mathrm{m}(c, d)$.

Immunoreactivity is still observable on $\mathrm{E} 18$ and $\mathrm{P} 0$ but not on P3. In the late fetal period, weak and diffuse 4D7 immunoreactivity may be observed within the habenular complex.

In addition to portions of the optic tract described above, the only other diencephalic sites of SNAP expression are the posterior commissure, detected on E15 (Fig. 11, $a, b$, open arrowheads), and the fornix, detected on E14 (Fig. 6, $a, b$ ). Immunoreactivity is too weak in these systems to make an adequate assessment of the time course of SNAP expression.

\section{Telencephalon}

The lateral olfactory tract shows a prolonged time course of SNAP expression similar to the fasciculus retroflexus and the optic nerve (E12-P0). The earliest detection of 4D7 immunoreactivity, E12, corresponds to the time that the tract is first identifiable in C2-stained sections. SNAP expression is confined to external portions of this tract (Fig. 12, c, d). Within the olfactory bulb, staining in the mitral cell layer and along trajectories of the mitral cell axons proximal to the lateral olfactory tract is undetectable on E12 and E13 but is present from E14 to E17 (Fig. 6a). Immunoreactivity with 4D7 declines below detectability in distal portions of the tract as it approaches the amygdala and molecular layer of the piriform cortex (e.g., see Fig. $11 a$ ), projections shown by $\mathrm{C} 2$ staining as early as E13 (see also Derer et al., 1977).

The anterior commissure is another coherent fiber tract of the telencephalon that exhibits 4D7 immunoreactivity. Staining is first detectable on E15, which is $1 \mathrm{~d}$ after it becomes evident with C2 staining (see also Wahlsten, 1982). Only a small component of the tract exhibits 4D7 immunoreactivity, and staining diminishes below detectability proximal to its diverse olfactoryrelated target or source structures (Haberly and Price, 1978). Immunoreactivity is lost between P0 and P3.

The other major telencephalic site of expression of SNAP is the intermediate zone of the cerebral cortex and hippocampus. Weak 4D7 immunoreactivity in the IZ beneath the cortical plate is first detectable on E14 (Figs. $6 a, 12 c$ ), and staining attains maximal intensity in the period from E15 to E17 (Fig. 11, a, c). The development and loss of 4D7 immunoreactivity follows an overall lateral-to-medial progression, which reflects the overall ontogenetic gradient for neocortex, e.g., histogenesis (Smart and Smart, 1982). Thus, 4D7 staining is greatest in the IZ of the lateral hemisphere on E14, but from E15 to E17 is pro-

Figure 10. Immunocytochemical staining of the superior and inferior colliculi in the interval E12-15. In paired micrographs, sections stained with 4D7 are on the left and with C2 on the right. $a$ and $b$, Coronal sections of the caudal superior colliculus on E12. The thin intermediate zone is stained with both antibodies. The wide ventricular matrix zones are negative with both antibodies (counterstaining reduced with blue filter in $b$ ). $c$ and $d$, Coronal sections through the superior colliculus on E15. Transversely oriented strands of 4D7 immunoreactivity correspond to the 

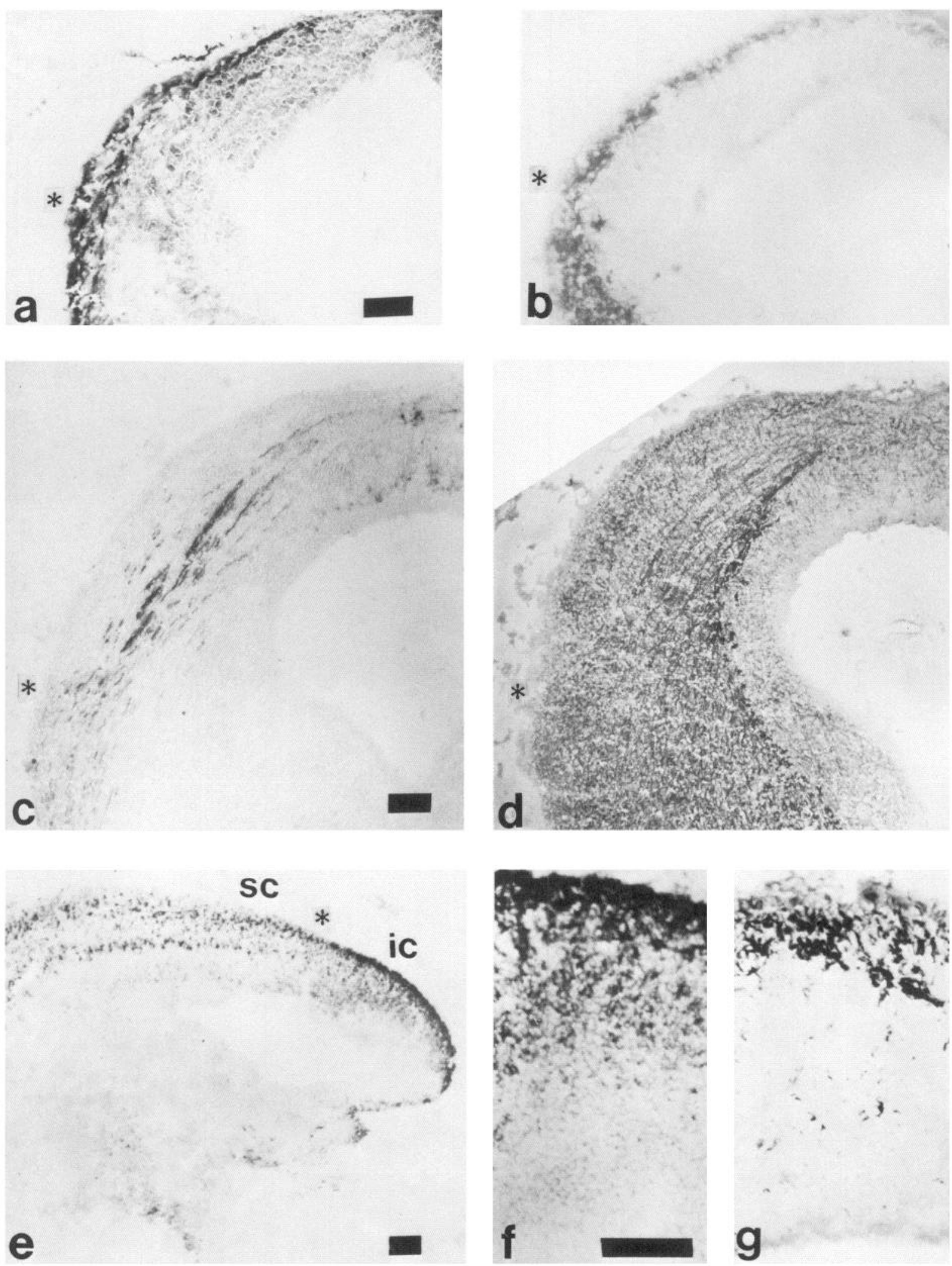

location of a superficial subset of similarly oriented C2-stained axons in the deep half of the intermediate zone (the stratum profundum). Asterisks in $a-d$ demarcate the approximate lateral boundary of the tectum with the lateral midbrain tegmentum. $e$, Sagittal section of the midbrain on E14 stained with 4D7 antibody. Rostral is to the left. The boundary between superior colliculus (sc) rostrally with the inferior colliculus (ic) caudally is indicated by an asterisk. The superficial band of punctate staining in the former corresponds to transversely oriented strands of immunoreactivity in the coronal plane. $f$ and $g$. Sagittal columns through the inferior colliculus. The dense superficial zone of 4D7 staining in $f$ (enlarged from section in $e$ ) matches the location of dense $\mathrm{C} 2$ immunoreactivity $(g)$, whereas the moderate 4D7 staining deeper in the intermediate zone appears to correspond to cells that do not show detectable $\mathrm{C} 2$ staining. Scale bars, $100 \mu \mathrm{m}(a-d, f, g)$ and $200 \mu \mathrm{m}(e)$. 

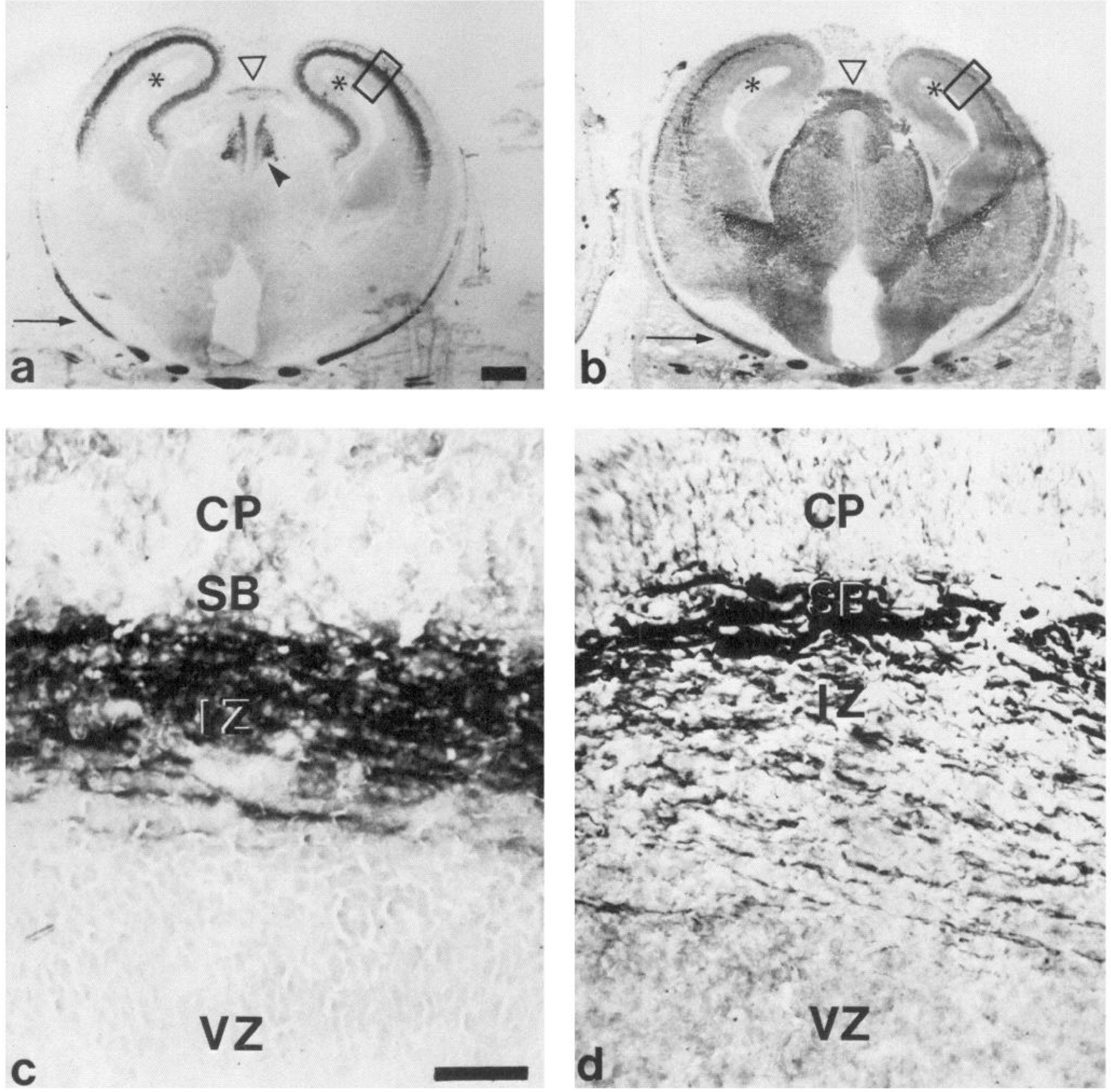

Figure 11. Immunocytochemical staining in the neocortex and hippocampus on E15. $a$ and $b$, Low-power photomicrographs of transverse sections through diencephalic and cortical regions stained with 4D7 $(a)$ and $\mathrm{C} 2(b)$. Asterisks mark the lateral ventricles. Immunoreactivity with 4D7 occupies a continuous band extending from dorsolateral neocortex through the hippocampus. Also visibly positive are the habenulae at the origin of the fasciculus retroflexus (arrowhead), the posterior commissure (at dorsomedial brain surface), and the optic nerves (ovoid densities near the base of the hypothalamus). The skull, denoted by arrows, appears dark due to heavy absorption of the cresyl violet counterstain. $c$ and $d$, Enlarged views of boxed areas shown in $a$ and $b$. Immunoreactivity with 4D7 is concentrated in the central regions of the intermediate zone (IZ), whereas C2-stained axons are most dense at the interface of the subplate $(S B)$ with the IZ. C2-stained fibers also course within the deep IZ and radially traverse the cortical plate $(C P)$, regions with no detectable 4D7 staining. Scale bars, $500 \mu \mathrm{m}(a, b)$ and $50 \mu \mathrm{m}(c, d)$.

gressively weaker laterally and stronger medially (Figs. $11 a$, $12 a$ ). By birth, only the IZ of the cingulate cortex and hippocampus exhibit immunoreactivity. No staining is detectable by P3.

As the IZ is a layer occupied by dense populations of afferent and efferent axons (Fig. 11, $b, d$; see also Crandall and Caviness, 1984), SNAP expression is potentially associated with some of these fibers. That $4 \mathrm{D} 7$ immunoreactivity has a reticular morphological appearance different from the pattern of $\mathrm{C} 2$ staining (Fig. 11, $c, d$ ). As in clearer examples of fiber tract staining, this does not in itself provide evidence against a localization to axons or their immediate environment. Consistent with an association with fiber systems, the dorsal portion of the corpus callosum exhibits prominent 4D7 immunoreactivity from E16 (Fig. 12a), the time of its first appearance with $\mathrm{C} 2$ staining (Fig. 12b). Also, the internal capsule, which contains afferents and efferents from neocortex, stains weakly from E18 to P0. That the internal capsule is negative for several days after its formation around E13 (Tello, 1934) is consistent with the findings in other fiber systems that express SNAP only along certain portions of their 

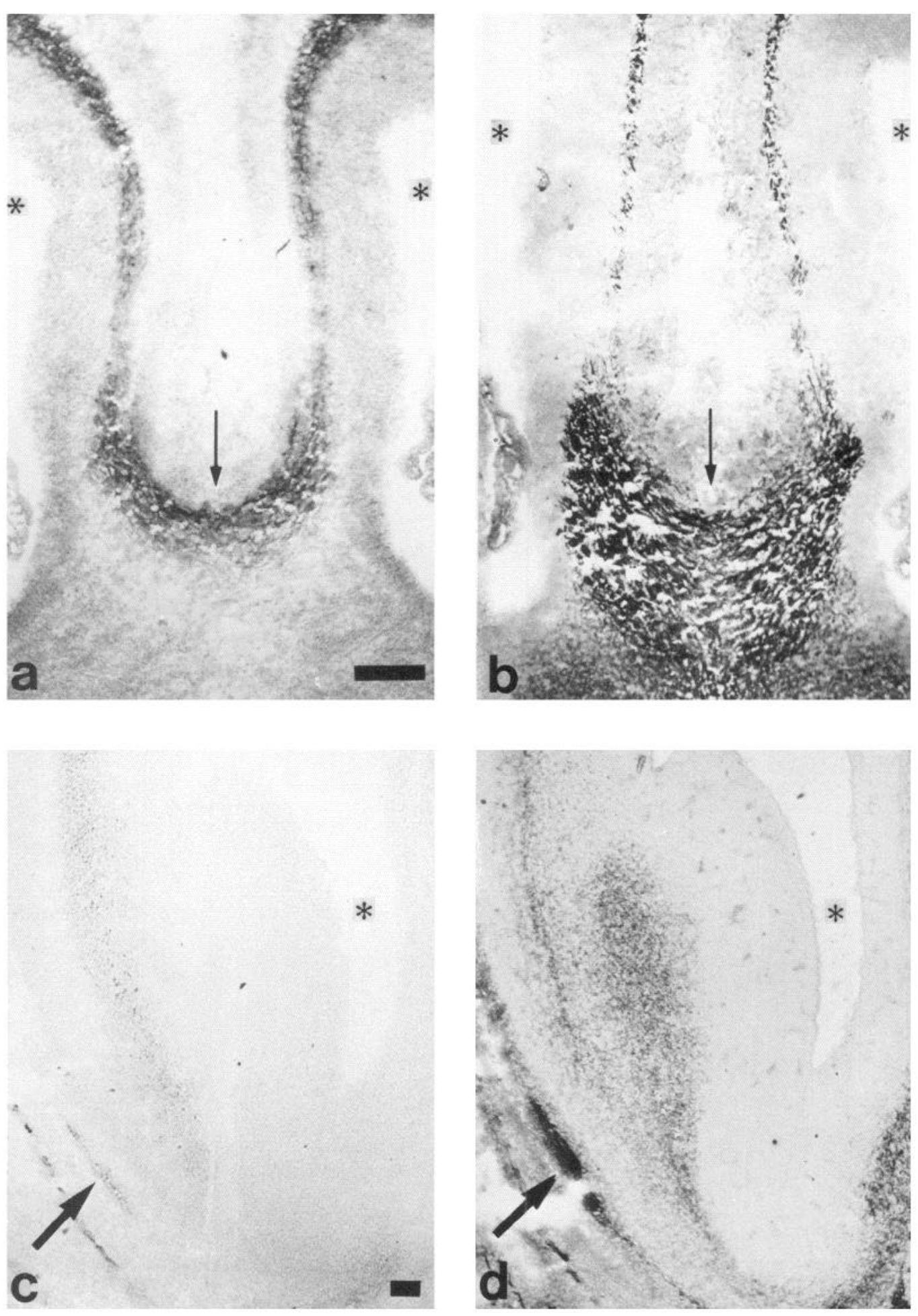

Figure 12. Restriction of 4D7 immunoreactivity to a subcomponent of 2 fiber tracts in the embryonic forebrain. Coronal sections stained with 4D7 and C2 antibodies are shown on the left and right, respectively. Asterisks mark the lateral ventricles. $a$ and $b$, Dorsomedial cortex and corpus callosum on E16. The intermediate zone, which stains with both antibodies, is continuous with the corpus callosum. Small arrows point to the decussation of the callosum, where it is clear that 4D7 staining occupies only a superficial portion of the zone containing crossing fibers. $c$ and $d$, Ventrolateral telencephalon on E14. Thick arrows point to the lateral olfactory tract, which exhibits 4D7 immunoreactivity only in an external portion of the bundle defined by $\mathrm{C} 2$ staining. The intermediate zone of piriform cortex also is positive with 4D7 (upper left), whereas the striatal anlage is negative (center). Scale bars, $100 \mu \mathrm{m}$.

trajectory. As another potential example of this phenomenon, the subplate and cortical plate show little 4D7 immunoreactivity, despite the presence of dense populations of C2-stained axon fascicles in the subplate and radially oriented fibers traversing the cortical plate (Fig. 11, $c, d$ ).
Despite these considerations, SNAP expression by migrating neurons that traverse the IZ (Caviness, 1982) cannot be ruled out as the locus of some or most of the 4D7 immunoreactivity present in this layer. Consistent with this possibility, observations in the neocortex of the homozygous reeler mutant mouse 

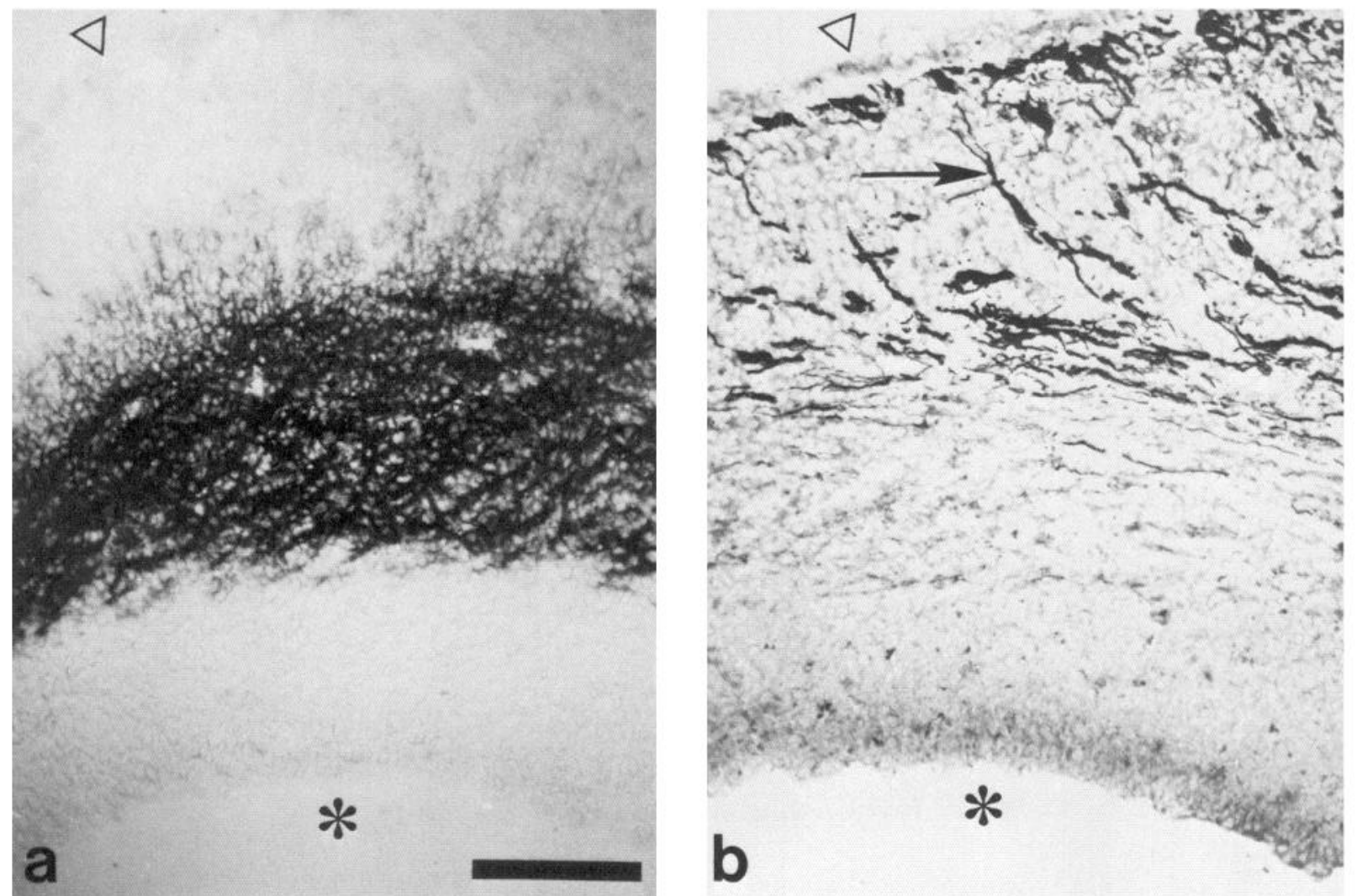

Figure 13. Large differences in the distribution of 4D7 and C2 immunoreactivity in the neocortex of the reeler mutant mouse on E16. Sectors through the wall of dorsolateral parietal cortex stained with 4D7 (a) and C2 (b). Triangles mark the pial surface; asterisks mark the lateral ventricles. The wide band of 4D7 immunoreactivity at an intermediate level contrasts with the relatively narrow layer of C2-stained fibers. Also, obliquely inclined axon fascicles (arrow in $b$ ) traversing more superficial regions are negative with 4D7. Scale bar, $50 \mu \mathrm{m}$.

provide clear evidence of a partial dissociation of the distribution of SNAP expression and that of axons. SNAP expression is intense in a broader zone of the neocortical wall, the deep portion of which contains very few C2-stained axons (Fig. 13, $a, b)$. Another result in the mutant is relevant to the issue of the selectivity of SNAP expression for fasciculated versus nonfasciculated axons. As well described for this mutant (e.g., PintoLord and Caviness, 1979), C2 staining reveals that aberrant fascicles of axons cross the cortical plate in oblique trajectories. However, alternate sections stained with the 4D7 antibody show that these fascicles are not associated with SNAP expression.

\section{Discussion}

The monoclonal antibody $4 \mathrm{D} 7$ recognizes protein antigens (SNAP) that are expressed selectively in the developing nervous system. Immunoreactivity is concentrated at the sites of a limited number of axonal systems in the fetal and perinatal mouse brain. The general validity of and exceptions to this inference will be discussed first. Subsequently, comparisons with previously described developmentally regulated nervous system antigens will be made. Finally, the possible functions and regulation of SNAP expression will be considered.

\section{Spatiotemporal patterns of SNAP expression}

\section{SNAP expression associated with axonal systems}

In almost all sites of SNAP expression, the earliest detection of 4D7 immunoreactivity either coincides with or follows shortly (1-2 d) the earliest expression of neurofilament immunoreactivity observed at the same locations by immunocytochemical staining of alternate sections with the monoclonal antibody $\mathrm{C} 2$. Thus, SNAP expression is generally confined to regions of the nervous system in which postmitotic neurons are forming axon tracts. Whereas $\mathrm{C} 2$ stains fiber systems in the developing nervous system without any obvious selectivity (e.g., compare with results of Tello, 1934, 1940, and Windle and Baxter, 1936, using classical silver stains), the distribution of 4D7 staining involves only a small subset of regions exhibiting neurofilament immunoreactivity. The schedules of appearance of 4D7 staining, like that for $\mathrm{C} 2$ staining, tend to follow general developmental gradients. For example, the expression of SNAP in the brain stem (E10-11) prior to the forebrain (E12-13) and the lateralto-medial progression within the cortex reflect overall ontogenetic sequences of both histogenesis and neuronal differentiation (Gardette et al., 1982; Jacobson, 1978; Smart and Smart, 1982).

SNAP expression is clearly localized within several developing axon tracts, including most, if not all, cranial nerves, the dorsal and ventral roots of the spinal cord, the ventral commissure and dorsal funiculus of the spinal cord, the lateral olfactory tract, the fasciculus retroflexus, the anterior commissure, the fornix, the posterior commissure, the ascending and descending tract of $\mathrm{V}$, and the corpus callosum. In addition, the expression of SNAP in portions of the intermediate zones of the fetal spinal cord, ventral rhombencephalon, cerebellum, colliculi, neocortex, and hippocampus overlaps the distribution of axon systems stained with $\mathrm{C} 2$ and exhibits continuity with 4D7 staining in discrete tracts containing axons afferent and efferent to these layers. Some of the many discrete fiber tracts that stain with $\mathrm{C} 2$ but not with 4D7 include the cerebral peduncle, the stria medullaris, the mammillothalamic tract, the stria termin- 
alis, and the medial lemniscus. Selectivity is evident even within certain positive fiber systems. For example, only portions of the corpus callosum, lateral olfactory tract and anterior commissure are immunoreactive. Despite these findings and the clear staining of neurites in vitro, the absence of electron-microscopic observations precludes definitive attribution of transient 4D7 immunoreactivity to axonal membranes only. The meshlike morphological appearance of 4D7 immunoreactivity in many sites is consistent with the possibility that SNAP is also expressed by the extracellular matrix or by processes of non-neuronal cells that lie along axonal paths (e.g., Altman and Bayer, 1984; Silver et al., 1982; Tosney and Landmesser, 1985).

A general feature of SNAP expression in the nervous system, both in vivo and in vitro, is that the intensity of immunoreactivity is weak or undetectable among the somata of origin of the axon systems associated with immunoreactivity. Whether this difference in distribution reflects differential localization of the proteins themselves or of antigenically distinct forms of the proteins is unclear at present. In addition to this differential antigen expression with respect to axons versus somata, intensity of 4D7 immunoreactivity often varies dramatically along the extent of axon tracts. A clear example is presented by the primary optic system. Relatively dense expression of SNAP occurs in the optic disk and stalk, but immunoreactivity declines below detectability both proximally within the optic fiber layer of the retina and distally within the optic tract. The contrast between the intense 4D7 staining in the cortical IZ and the very weak and/or brief staining at the sites of afferents or efferents to this layer within the internal capsulc, subplatc, and cortical plate may reflect a similar differential expression of SNAP along axon pathways. In several other systems, SNAP expression declines in intensity at the point at which large axon fascicles break up into smaller fascicles within target structures. For example, 4D7 immunoreactivity is never observed in the target structures of the fasciculus retroflexus, lateral olfactory tract, fornix, olfactory nerve, and anterior commissure. In contrast to the CNS, 4D7 staining of peripheral nerves shows immunoreactivity all along their course.

Although the onset of SNAP expression in diverse structures correlates with the time of axon tract formation, simple generalizations about the timing of loss of expression are difficult to make. Comparison of the duration of 4D7 immunoreactivity with respect to neuroectodermal origin yields no consistent pattern. For example, systems showing a prolonged period of SNAP expression (i.e., several days) include axon tracts deriving from the retina (neural plate derivative), from the trigeminal ganglion (largely a placodal derivative), and from spinal dorsal root ganglia (neural crest derivative) (LeDouarin, 1982). Given that SNAP expression is brief ( $1 \mathrm{~d}$ ) among nerves arising from spinal motoneurons and certain cranial motor nuclei-such as the facial, oculomotor and hypoglossal nuclei-it is possible that duration of expression is in some way related to sensory versus motor modality of the system. A clear exception, however, is presented by the acousticovestibular nerve, a sensory cranial nerve that shows weak SNAP expression for only $1 \mathrm{~d}$ or less. Despite these differences among systems in the timing of loss of SNAP expression, SNAP immunoreactivity disappears mostly prior to target innervation, myelination, and synaptogenesis, which are largely postnatal events (Jacobson, 1978; Jones, 1983).

\section{Evidence for SNAP expression not associated with axons}

Some of the SNAP immunoreactivity expressed in the intermediate zones of fetal CNS structures is conceivably not localized to growing axons or their immediate environment. As migrating neurons traverse these zones in transit from the germinal ventricular zones (Altman and Bayer, 1984; Caviness, 1982; Edwards et al., 1986b; Miale and Sidman, 1961; Nornes and Carry, 1978; Stanfield and Cowan, 1979), the possibility that at least some of the immunoreactivity observed is localized to these cells should be considered. This appears unlikely for the spinal cord and superior colliculus, structures in which the morphological appearance of 4D7 immunoreactivity takes the form of elongated strands resembling C2-stained axon fascicles of the commissural associational pathway in the cord (Holley, 1982; Wentworth, 1984b) and of the anlage of the stratum profundum of the deep colliculus (Edwards et al., 1986b), respectively. However, such an exclusive localization to axon systems is not readily apparent in the intermediate zones of the ventral rhombencephalon, cerebellum, inferior colliculus, neocortex, and hippocampus.

Complete dissociation of SNAP expression from axonal systems is evident in at least 1 structure, the postnatal cerebellum. Following a late fetal period in which SNAP expression is absent in the cerebellum, 4D7 immunoreactivity reappears in the neonatal period within the deep portion of the external granular layer. This zone is occupied by premigratory granule cells and few, if any, axons (Altman, 1972; Miale and Sidman, 1961; Ramon y Cajal, 1909-1911).

\section{Comparison with other stage- and region-specific antigens}

The 4D7 antibody recognizes 3 protein species of 150-160, 100110 , and $80 \mathrm{kDa}$. As yet, it is not known whether they are glycoproteins, nor is it known whether the epitope recognized by the 4D7 antibody is a peptide or a carbohydrate structure. Of the diverse developmentally regulated antigens previously described, including a few that have molecular weights similar to 1 or more of the SNAP antigens, none exhibits the same spatiotemporal pattern of expression.

The glycoproteins neuron-glia cell adhesion molecules $(\mathrm{Ng}-$ CAM), neural cell adhesion molecule (N-CAM/D2/BSP2), L1, and nerve growth factor-inducible large external glycoprotein (NILE) are considered to comprise an antigenically related family of cell adhesion molecules. Although antibodies to these molecules all recognize glycoproteins in the range of 180-230 $\mathrm{kDa}, 2$ bind additionally to protein species similar in size to SNAP antigens: anti-Ng-CAM and -Ll recognize a 135-140 $\mathrm{kDa}$ species; anti-N-CAM recognizes a $120 \mathrm{kDa}$ protein; and anti-N-CAM and -Ng-CAM recognize an $80 \mathrm{kDa}$ species (Chuong et al., 1982; Faissner et al., 1984a, b; Grumet et al., 1984; Hirn et al., 1983; Jorgensen et al., 1980; Salton et al., 1983b; Stallcup and Beasley, 1985b; Williams et al., 1985a). Immunocytochemical studies with antibodies recognizing the glycoproteins NILE and $\mathrm{Ng}-\mathrm{CAM}$ reveal an in vivo pattern of expression in rat and chick, respectively, that resembles SNAP in their association with axon systems around the time of neurofilament protein expression (Daniloff et al., 1986; Thiery et al., 1985; Stallcup et al., 1985). Both antibodies, like 4D7 antibody, stain predominantly the plasma membrane of neurites from cultured neurons (Grumet and Edelman, 1984; Grumet et al., 1984; Salton et al., 1983a; Stallcup et al., 1985). However, unlike our results on SNAP, NILE and Ng-CAM appear to be expressed in most axon systems and developmental reductions in their prevalence appear to occur postnatally. Also, immunoreactivity in some sites persists to maturity (e.g., PNS fiber systems and unmyelinated fiber tracts such as the olfactory nerve). Unlike the 4D7 antibody, antibodies to N-CAM stain diverse ectodermal and mesodermal derivative structures, including widespread regions of the developing nervous system (Chuong et al., 1982; Crossin et al., 1985; Edelman et al., 1983; Hirn et al., 1983; Rougon et al., 1982; Williams et al., 1985a, b) and both neurons and glia in tissue culture (Jorgensen et al., 1980; Noble et al., 1985; Rutishauser, 1985; Williams et al., 1985a, b). In comparison, an antibody recognizing only the large N-CAM species (Pollerberg et al., 1985) and antibodies to L1 (Faissner et al., 1984a, b; Fushiki and Schachner, 1986) more specifically stain layers of differentiating neurons in the fetal rodent CNS, yet again 
immunoreactivity is not clearly restricted to subsets of neurons, is not selectively concentrated in axon tracts, and is not transient. Despite the clear differences from SNAP in the patterns of expression of these antigens, it is nevertheless possible that the 4D7 antibody recognizes subtypes of the genetically related family of cell adhesion molecules.

Other antigens have been demonstrated to exhibit a relatively selective association with developing axons. An antibody generated against isolated growth-cone particles, which recognizes a $185-255 \mathrm{kDa}$ sialoglycoprotein (Ellis et al., 1985; Wallis et al., 1985), stains axonal membranes similar to NILE and NgCAM. Again, unlike the expression of SNAP, most axons appear to be immunoreactive in fetal brain and some staining persists to adulthooa. Another antigen of unknown molecular weight has been shown immunocytochemically to be expressed nonselectively among axon tracts of the chick spinal cord and periphery during or shortly after their formation and to be reduced to low levels in late embryogenesis (Fujita and Obata, 1984). An intracellular antigen of $180 \mathrm{kDa}$ has been shown to exhibit a similar pattern of expression in the developing rat spinal cord (Hockfield and McKay, 1985). In contrast, other antigens have been shown to be expressed in association with subsets of developing fiber systems in the chick spinal cord, 2 of which have molecular weights similar to SNAP species, 142 and $155 \mathrm{kDa}$ (Tanaka and Obata, 1984). However, expression persists in white matter at maturity. Another protein, also around $140 \mathrm{kDa}$, appears to occur selectively in axon-rich strata of the embryonic chick retina, the optic fiber, and inner plexiform layers, and to undergo a large developmental reduction in expression (Cole and Glaser, 1984). By comparison, SNAP is expressed in the mouse retina very weakly in the optic fiber layer and not at all in the inner plexiform layer. Finally, a few proteins in mammalian and nonmammalian vertebrates have been shown to be shipped anterogradely by fast axonal transport at elevated rates during periods of axonal growth and at reduced rates after target innervation ("growth associated proteins," or GAPs) (Willard et al., 1985). In comparison to the SNAP, the 2 most prominent GAPs (44 and 23-24 kDa) are smaller and undergo decreases in synthesis and transport relatively later (i.e., postnatal epoch in rabbits).

From the foregoing review, it is clear that the present demonstration of antigens transiently expressed in association with a restricted number of axonal systems during tract formation is unique in the vertebrate nervous system. The closest parallel to these findings comes from work in invertebrates demonstrating that subsets of axon fascicles in the embryo of Aplysia and the grasshopper are selectively associated with particular antigens (Goodman et al., 1984; McKay et al., 1984).

\section{Function and regulation of SNAP antigens}

The localization and schedule of expression of the SNAP antigens conform to what might be expected for proteins that regulate axonal outgrowth in the pathways between afferent structures and target fields. This possibility is directly supported by preliminary studies demonstrating that the 4D7 antibody blocks neurite outgrowth by brain stem cells in vitro (Yamamoto et al., 1985). The in vivo expression of SNAP along nerve trunks suggests a more likely role in promoting axon fasciculation rather than elongation per se. Evidence for the function of other axon-associated antigens in promoting axon fasciculation has been provided by perturbation of axon bundling patterns in vitro following introduction of antibodies to N-C.AM, NILE, and L1 (Fischer et al., 1986; Jorgensen et al., 1980; Rutishauser and Edelman, 1980; Rutishauser et al., 1978, 1985; Stallcup and Beasley, 1985a). Moreover, injection of antibodies to N-CAM (Fab's) into the embryonic chick eye disrupts orderly patterns of optic axon fasciculation (Thanos et al., 1984) and causes the axons to lose their association with the ventral marginal zone of the optic stalk (Silver and Rutishauser, 1984). Similar ex- periments need to be done to assess whether SNAP also plays a role in fiber fasciculation.

The association of SNAP expression with only a few fiber systems may provide an important clue to its function. The SNAP antigens could potentially serve as a marker to direct advancing axons into and along the appropriate axon fascicles. Evidence for such an antigen-coded implementation of selective axon fasciculation has been presented for the grasshopper embryo (Goodman et al., 1984).

The SNAP antigen located in the deep portions of the external granular layer of postnatal cerebellum and in the intermediate zone of fetal cerebral cortex may subserve a completely different function from SNAP associated more exclusively with axon systems. For example, it may be involved in the regulation of migration of the cells from these zones into the inner granular layer and cortical plate, respectively. In vitro studies have suggested such a role for the L1 antigen in the cerebellum, which is also expressed intensely in the inner portion of the external granular layer (Lindner et al., 1983). The possibility of distinct functions for SNAP antigens raises the general question of whether the same or different members of the set of immunoreactive proteins are expressed at various sites in the nervous system.

The regulation of the loss of SNAP expression in development is an intriguing problem for future research. It is possible that the developmental loss of 4D7 staining reflects a change in antigenicity by posttranslational modification of the protcins. Alternatively, some form of interaction of axons with elements in their pathway or in their targets may shut off either the synthesis or axonal transport of SNAP. If so, variation in the timing of such interactive events among different axonal systems might account for the observed variation in the timing of loss of expression. Of relevance to this hypothesis, the transport of one set of GAPs, which resemble SNAP in their size range (110-140 $\mathrm{kDa}$ ), shows a persistent elevation when the tectal target has been surgically ablated (Benowitz et al., 1983). Experiments of this kind might fruitfully be applied to the similar question of whether reduction of SNAP expression is regulated by axontarget interactions.

\section{References}

Altman, J. (1972) Postnatal development of the cerebellar cortex in the rat. I. The external germinal layer and the transitional molecular layer. J. Comp. Neurol. 145: 353-398.

Altman, J., and S. A. Bayer (1984) The development of the rat spinal cord. Adv. Anat. Emb. Cell Biol. 85: 1-164.

Altman, J., and S. A. Bayer (1985) Embryonic development of the rat cerebellum. II. Translocation and regional distribution of the deep neurons. J. Comp. Neurol. 231: 27-41.

Ayer-LeLievre, C., D. Dahl, H. Björklund, and A. Seiger (1985) Neurofilament immunoreactivity in developing rat autonomic and sensory ganglia. Int. J. Dev. Neurosci. 4: 385-399.

Benowitz, L. I., M. G. Yoon, and E. R. Lewis (1983) Transported proteins in the regenerating optic nerve: Regulation by interactions with the optic tectum. Science 222: 185-188.

Berg, D. K. (1984) New neuronal growth factors. Annu. Rev. Neurosci. 7: $144-170$.

Byrne, M. C., R. W. Ledeen, F. J. Roisen, G. Yorke, and J. R. Sclafani (1983) Ganglioside-induced neuritogenesis: Verification that gangliosides are the active agents, and comparison of molecular species. J. Neurochem. 41: 1214-1222.

Brockhaus, M., J. L. Magnani, M. Blaszczyk, Z. Steplewski, H. Koprowski, K. A. Karlsson, G. Larsson, and V. Ginsburg (1981) Monoclonal antibodies directed against the human $\mathrm{Le}^{\mathrm{b}}$ group antigen. J. Biol. Chem. 256: 13223-13229.

Carbonetto, $S$. (1984) The extracellular matrix of the nervous system. Trends Neurosci. 7: 382-387.

Caviness, V. S., Jr. (1982) Neocortical histogenesis in normal and recler micc: A developmental study based upon [ $\left.{ }^{3} \mathrm{H}\right]$ thymidine autoradiography. Dev. Brain Res. 4: 293-302.

Chuong, C.-M., D. A. McClain, P. Streit, and G. M. Edelman

(1982) 
Neural cell adhesion molecules in rodent brains isolated by monoclonal antibodies with cross-species reactivity. Proc. Natl. Acad. Sci. USA 79: 4234-4238.

Cochard, P., and D. Paulin (1984) Initial expression of neurofilaments and vimentin in the central and peripheral nervous system of the mouse embryo in vivo. J. Neurosci. 4: 2080-2094.

Cole, G. J., and L. Glaser (1984) Identification of novel neural- and neural retina-specific antigens with a monoclonal antibody. Proc. Natl. Acad. Sci. USA 81: 2260-2264.

Crandall, J. E., and V. S. Caviness, Jr. (1984) Axon strata of the cerebral wall in embryonic mice. Dev. Brain Res. 14: 185-195.

Crossin, K. L., C.-M. Chuong, and G. M. Edelman (1985) Expression sequences of cell adhesion molecules. Proc. Natl. Acad. Sci. USA 82: 6942-6946.

Daniloff, J. K., C.-M. Chuong, G. Levi, and G. M. Edelman (1986) Differential distribution of cell adhesion molecules during histogenesis of the chick nervous system. J. Neurosci. 6: 739-758.

Derer, P., V. S. Caviness, Jr., and R. L. Sidman (1977) Early cortical histogenesis in the primary olfactory cortex of the mouse. Brain Res. 123: 27-40.

Edelman, G. M., W. J. Gallin, A. Delouvee, B. A. Cunningham, and J.-P. Thiery (1983) Early epochal maps of two different cell adhesion molecules. Proc. Natl. Acad. Sci. USA 80: 4384-4388.

Edwards, M. A., and M. Yamamoto (1985) Transient expression of antigens in the primary optic pathways of the fetal mouse. Soc. Neurosci. Abstr. 11: 316.

Edwards, M. A., G. E. Schneider, and V. S. Caviness, Jr. (1986a) Development of the crossed retinocollicular projection in the mouse. J. Comp. Neurol. 248: 410-421.

Edwards, M. A., V. S. Caviness, Jr., and G. E. Schneider (1986b) Development of cell and fiber lamination in the mouse superior colliculus. J. Comp. Neurol. 248: 395-409.

Ellis, L., I. Wallis, E. Abreu, and K. H. Pfenninger (1985) Nerve growth cones isolated from fetal rat brain. IV. Preparation of a membrane subfraction and identification of a membrane glycoprotein expressed on sprouting neurons. J. Cell Biol. 101: 1977-1989.

Faissner, A., J. Kruse, J. Nieke, and M. Schachner (1984a) Expression of neural cell adhesion molecule L1 during development in neurological mutants and in the peripheral nervous system. Dev. Brain Res. 15: 69-82.

Faissncr, A., J. Kruse, C. Goridis, E. Bock, and M. Schachner (1984b) The neural cell adhesion molecule $\mathrm{Ll}$ is distinct from the N-CAM related group of surface antigens BSP-2 and D2. EMBO J. 3: 733737.

Fischer, G., V. Künemund, and M. Schachner (1986) Neurite outgrowth patterns in cerebellar microexplant cultures are affected by antibodies to the cell surface glycoprotein L1. J. Neurosci. 6: 605612.

Fujita, S. C., and K. Obata (1984) Monoclonal antibodies demonstrate regional specificity in the spinal funiculi of the chick embryo. Neurosci. Res. 1: 131-148.

Fushiki, S., and M. Schachner (1986) Immunocytochemical localization of cell adhesion molecules L1 and N-CAM and the shared carbohydrate epitope L2 during development in the mouse neocortex. Dev. Brain Res. 24: 153-167.

Gardette, R., M. Courtois, and J.-C. Bisconte (1982) Prenatal development of mouse central nervous structures: Time of neuron origin and gradients of neuronal production. A radioautographic study. J. Hirnforsch. 23: 415-431.

Goodman, C. S., M. J. Bastiani, C. Q. Doe, S. duLac, S. L. Helfand, J. Y. Kuwada, and J. B. Thomas (1984) Cell recognition during neuronal development. Science 225: 1271-1279.

Grumet, M., and G. M. Edelman (1984) Heterotypic adhesion is inhibited by antibodies to neural determinants. Science 222: 60-62.

Grumet, M., S. Hoffman, and G. M. Edelman (1984) Two antigenically related neuronal cell adhesion molecules of different specificities mediate neuron-neuron and neuron-glia adhesion. Proc. Natl. Acad. Sci. USA 81: 267-271.

Haberly, L. B., and J. L. Price (1978) Association and commissural fiber systems of the olfactory cortex of the rat. II. Systems originating in the olfactory peduncle. J. Comp. Neurol. 181: 781-808.

Henke-Fahle, S., and F. Bonhoeffer (1983) Inhibition of axonal growth by a monoclonal antibody. Nature 303: 65-67.

Hinds, J. W. (1972) Early neuron differentiation in the mouse olfactory bulb. II. Electron microscopy. J. Comp. Neurol. 146: 253-276.

Hirn, M., M. S. Ghandour, H. Deagostini-Bazin, and C. Goridis (1983) Molecular heterogeneity and structural evolution during cerebellar ontogeny detected by monoclonal antibody of the mouse cell surface antigen BSP-2. Brain Res. 265: 87-100.

Hockfield, S., and R. D. G. McKay (1985) Identification of major cell classes in the developing mammalian nervous system. J. Neurosci. 5: 3310-3328.

Holley, J. A. (1982) Early development of the circumferential axonal pathway in mouse and chick spinal cord. J. Comp. Neurol. 205: 371382.

Holley, J. A., H. O. Nornes, and M. Morita (1982a) Guidance of neuritic growth in the transverse plane of embryonic mouse spinal cord. J. Comp. Neurol. 205: 360-370.

Holley, J. A., C. C. Wimer, and J. E. Vaughn (1982b) Quantitative analyses of neuronal development in the lateral motor column of mouse spinal cord. III. Generation and settling patterns of large and small neurons. J. Comp. Neurol. 207: 333-343.

Jacobson, M. (1978) Developmental Neurobiology, 2nd ed., Plenum, New York.

Jones, D. G. (1983) Development, maturation and aging of synapses. Adv. Cell. Neurobiol. 4: 163-222.

Jorgensen, O. S., A. Delouvee, J.-P. Thiery, and G. Edelman (1980) The nervous system specific protein D2 is involved in adhesion among neurites from cultured rat ganglia. FEBS Lett. 111: 39-42.

Köhler, G., and M. Milstein (1975) Continuous cultures of fused cells secreting antibody of predefined specificity. Nature 256: 495-497.

Lauder, J. M., and F. E. Bloom (1974) Ontogeny of monoamine neurons in the locus coeruleus, raphe nuclei and substantia nigra of the rat. I. Cell differentiation. J. Comp. Neurol. 155: 469-482.

Ledeen, R. W., and L. F. Eng (1973) Gangliosides of human myelin: Sialosilgalactosylceramide (G7) as a major component. J. Neurochem. 21: 829-839.

LeDouarin, N. M. (1982) The Neural Crest, Cambridge U. P., New York.

Lindner, J., F. Rathjen, and M. Schachner (1983) L1 mono- and polyclonal antibodies modify cell migration in early postnatal mouse cerebellum. Nature 305: 427-430.

Liposits, Z., G. Setalo, and B. Flerko (1984) Application of the silvergold intensified 3-3'-diaminobenzidine chromogen to the light and electron microscopic detection of the luteinizing hormone releasing hormone system of the rat brain. Neuroscience 13: 513-525.

McKay, R. D. G., S. Hockfield, J. Johansen, I. Thompson, and K. Frederickson (1984) Surface molcculcs identify groups of growing axons. Science 222: 678-684.

Miale, I. L., and R. L. Sidman (1961) An autoradiographic analysis of histogenesis in the mouse cerebellum. Exp. Neurol. 4: 277-296.

Noble, M., M. Albrechtsen, C. Moller, J. Lyles, E. Bock, C. Goridis, M. Watanabe, and U. Rutishauser (1985) Glial cells express N-CAM D2-CAM-like polypeptides in vitro. Nature 316: 725-728.

Nornes, H. O., and M. Carry (1978) Neurogenesis in spinal cord of mouse: An autoradiographic analysis. Brain Res. 159: 1-16.

Pinto-Lord, M. C., and V. S. Caviness, Jr. (1979) Determinants of cell shape and orientation: A comparative Golgi analysis of cell-axon interrelationships in the developing neocortex of normal and reeler mice. J. Comp. Neurol. 187: 49-70.

Pollerberg, E. G., R. Sadoul, C. Goridis, and M. Schachner (1985) Selective expression of the $180-\mathrm{kD}$ component of the neural cell adhesion molecule N-CAM during development. J. Cell Biol. 101: 19211929.

Ramon y Cajal, S. (1909-1911) Histologie du Système Nerveux de l'Homme et des Vertébrés (reprinted 1972 by the Institute Ramon y Cajal del C.S.I.C., Madrid).

Repetto-Antoine, M., and V. Meininger (1982) Histogenesis of the inferior colliculus in rat. Anat. Embryol. 165: 19-37.

Rosner, H., M. Al-Aqtum, and S. Henke-Fahle (1985) Developmental expression of GD3 and polysialogangliosides in embryonic chicken nervous tissue reacting with monoclonal antiganglioside antibodies. Dev. Brain Res. 18: 85-95.

Rougon, G., H. Deagostini-Bazin, M. Hirn, and C. Goridis (1982) Tissue- and developmental stage-specific forms of a neural cell surface antigen linked to differences in glycosylation of a common polypeptide. EMBO J. 10: 1239-1244.

Rutishauser, U., and G. E. Edelman (1980) Effects of fasciculation on the outgrowth of neurites from spinal ganglia in culture. J. Cell Biol. 87: $370-378$.

Rutishauser, U., W. E. Gall, and G. M. Edelman (1978) Adhesion among neural cells of the chick embryo. 1 . Role of the cell surface molecule CAM in the formation of neurite bundles in cultures of spinal ganglion. J. Cell Biol. 97: 145-152. 
Rutishauser, U., M. Watanabe, J. Silver, F. A. Troy, and E. R. Vimr (1985) Specific alteration of N-CAM-mediated cell adhesion by an endoneuraminidase. J. Cell Biol. 101: 1842-1849.

Salton, S. R. J., C. Richter-Landsberg, L. ^. Greene, and M. L. Shelanski (1983a) Nerve growth factor-inducible large external (NILE) glycoprotein: Studies of a central and peripheral neuronal marker. J. Neurosci. 3: 441-454.

Salton, S. R. J., Shelanski, M. L., and L. A. Greene (1983b) Biochemical properties of the nerve growth factor-inducible (NILE) glycoprotein. J. Neurosci. 3: 2420-2430.

Schoenwolf, G. C. (1984) Histological and ultrastructural studies of secondary neurulation in mouse embryos. Am. J. Anat. 169: 361376.

Silver, J. (1984) Studies on the factors that govern directionality of axonal growth in the embryonic optic nerve and at the chiasm of mice. J. Comp. Neurol. 223: 238-251.

Silver, J., and Rutishauser, U. (1984) Guidance of optic axons in vivo by a performed adhesive pathway on neuroepithelial endfeet. Dev. Biol. 106: 485-499.

Silver, J., S. E. Lorenz, O. Wahlsten, and J. Coughlin (1982) Axonal guidance during development of the great cerebral commissures: Descriptive and experimental studies, in vivo, on the role of preformed glial pathways. J. Comp. Neurol. 210: 10-29.

Sims, T. J., and J. E. Vaughn (1979) The generation of neurons involved in early reflex pathway in embryonic mouse spinal cord. J. Comp. Neurol. 183: 707-720.

Smart, I. H. M., and M. Smart (1982) Growth patterns in the lateral wall of the mouse telencephalon: I. Autoradiographic studies of the histogenesis of the isocortex and adjacent areas. J. Anat. 134: 273298.

Stallcup, W. B., and L. Beasley (1985a) Involvement of the nerve growth factor-inducible large external glycoprotein (NILE) in ncurite fasciculation in primary cultures of rat brain. Proc. Natl. Acad. Sci. USA 82: 1276-1280.

Stallcup, W. B., and L. Beasley (1985b) Polymorphism among NILErelated glycoproteins from different types of neurons. Brain Res. 346: 287-293.

Stallcup, W. B., L. L. Beasley, and J. M. Levine (1985) Antibody against nerve growth factor-inducible large external (NILE) glycoprotein labels nerve fiber tracts in the developing rat nervous system. $J$. Neurosci. 5: 1090-1101.

Stanfield, B. B., and W. M. Cowan (1979) The development of the hippocampus and dentate gyrus in normal and reeler mice. J. Comp. Neurol. 185: 423-460.

Tanaka, H., and K. Obata (1984) Developmental changes in unique cell surface antigens of chick embryo spinal motoneurons and ganglion cells. Dev. Biol. 106: 26-37.

Tello, J. F. (1934) Les differenciations neurofibrillares dans le prosencephale de la souris de 4 à 15 millimetres. Trav. Lab. Rech. Biol. Univ. Madrid 29: 338-395.

Tello, J. F. (1940) Histogenese du cervelet et ses voies chez la souris blanche. Trab. Inst. Cajal Invest. Biol. 32: 1-72.
Thanos, S., F. Bonhoeffer, and U. Rutishauser (1984) Fiber-fiber interactions and tectal cues influence the development of the chick retinotectal projection. Proc. Natl. Acad. Sci. USA 81: 1906-1910.

Thiery, J.-P., A. Delouvee, M. Grumet, and G. M. Edelman (1985) Initial appearance and regional distribution of the neuron-glia cell adhesion molecule in the chick embryo. J. Cell Biol. 100: 442-456.

Thoenen, H., and D. Edgar (1985) Neurotrophic factors. Science 229. 238-242.

Tosney, K. W., and L. T. Landmesser (1985) Development of the major pathways for neurite outgrowth in the chick hindlimb. Dev. Biol. 109: 193-214.

Towbin, H., T. Staehelin, and J. Gordon (1979) Electrophoretic transfer of proteins from polyacrylamide gels to nitrocellulose sheets: Procedure and some applications. Proc. Natl. Acad. Sci. USA 76:43504354.

Wahlsten, D. (1982) Prenatal schedule of appearance of mouse brain commissures. Dev. Brain Res. 1: 461-474.

Wahlsten, D., and P. Wainwright (1977) Application of a morphological time scale to hereditary differences in prenatal mouse development. J. Embryol. Exp. Morphol. 42: 79-92.

Wallis, I., L. Ellis, K. Suh, and K. H. Pfenninger (1985) Immunolocalization of a neuronal growth-dependent membrane glycoprotein. J. Cell Biol. 101: 1990-1998.

Wentworth, L. E. (1984a) The development of the cervical spinal cord of the mouse embryo. I. A Golgi analysis of ventral root neuron differentiation. J. Comp. Neurol. 222: 81-95.

Wentworth, L. E. (1984b) The development of the cervical spinal cord of the mouse embryo: II. A Golgi analysis of sensory, commissural, and association cell differentiation. J. Comp. Neurol. 222: 96-115.

Wentworth, L. E., and J. W. Hinds (1978) Early motoneuron formation in the cervical spinal cord of the mouse: An electron microscopic, scrial scction analysis. J. Comp. Ncurol. 177: 611-634.

Willard, M. B., K. Meiri, and M. Glicksman (1985) "Changes of state during neuronal development: Regulation of axon elongation." In Molecular Bases of Neural Development, G. M. Edelman, W. E. Gall, and W. M. Cowan, eds., pp. 341-361, Wiley, New York.

Williams, M. A., and R. H. McClure (1980) The use of Sep-Pak C18 cartridge during isolation of gangliosides. J. Neurochem. 35: 266269.

Williams, R. K., C. Goridis, and R. Akeson (1985a) Individual neural cell types express immunologically distinct N-CAM forms. J. Cell Biol. 101: 36-42.

Williams, R. K., P. T. Kelly, and R. A. Akeson (1985b) Cell-surface antigens of developing rat cerebellar neurons: Identification with monoclonal antibodies. Dev. Brain Res. 19: 253-266.

Windle, W. F., and R. E. Baxter (1936) The first neurofibrillar development in albino rat embryos. J. Comp. Neurol. 63: 173-187.

Yamamoto, M., A. M. Boyer, H. Tanaka, and J. N. Wood (1985) An antibody which blocks outgrowth of a subpopulation of neurites. Soc. Neurosci. Abstr. 11: 763. 